Portland State University

PDXScholar

7-15-2021

\title{
Marijuana-related Crime in Oregon Following Legalization of Recreational Use
}

Ana Alicia Soto

Portland State University

Follow this and additional works at: https://pdxscholar.library.pdx.edu/open_access_etds

Part of the Criminology and Criminal Justice Commons, and the Food and Drug Law Commons Let us know how access to this document benefits you.

\section{Recommended Citation}

Soto, Ana Alicia, "Marijuana-related Crime in Oregon Following Legalization of Recreational Use" (2021). Dissertations and Theses. Paper 5731.

https://doi.org/10.15760/etd.7602

This Thesis is brought to you for free and open access. It has been accepted for inclusion in Dissertations and Theses by an authorized administrator of PDXScholar. Please contact us if we can make this document more accessible: pdxscholar@pdx.edu. 
Marijuana-related Crime in Oregon Following Legalization of Recreational Use

by

Ana Alicia Soto

A thesis submitted in partial fulfillment of the requirements for the degree of

\author{
Master of Science \\ in \\ Criminology and Criminal Justice
}

Thesis Committee:

Kris Henning, Chair

Mauri Matsuda

Christopher Campbell

Portland State University 


\begin{abstract}
In this decade we are seeing the legalization of recreational marijuana occurring across the nation, with new legislation being passed every year. This necessitates research into what works within the regulatory framework of states where MJ has been legalized. This study sets out to look at Oregon's implementation of recreational marijuana and its impact on marijuana-related offenses. Using NIBRS, we examine marijuana-related offenses across 13 counties with crime data from 41 agencies in Oregon from prelegalization to post-legalization (2010 to 2019). This study uses elements of legalization - licenses, and production to analyze the association between these aspects and offenses that are still illegal under legalization. This study finds that marijuana-related offenses are associated with the quantity of production and the number of licenses. Additionally, this study finds that legalization may only have a minimal impact on certain types of marijuana-related offenses.
\end{abstract}




\section{Acknowledgments}

This project would not have been manageable without the support and guidance of Dr. Henning, as we maneuvered through creating this document and gathering data. I appreciate the time he took to facilitate the gathering of the data used in this study, the

feedback, and the skills that made digesting the data easier. I would also like to thank my committee members Dr. Matsuda and Dr. Campbell for providing resources and ideas that helped shape aspects of this project. 


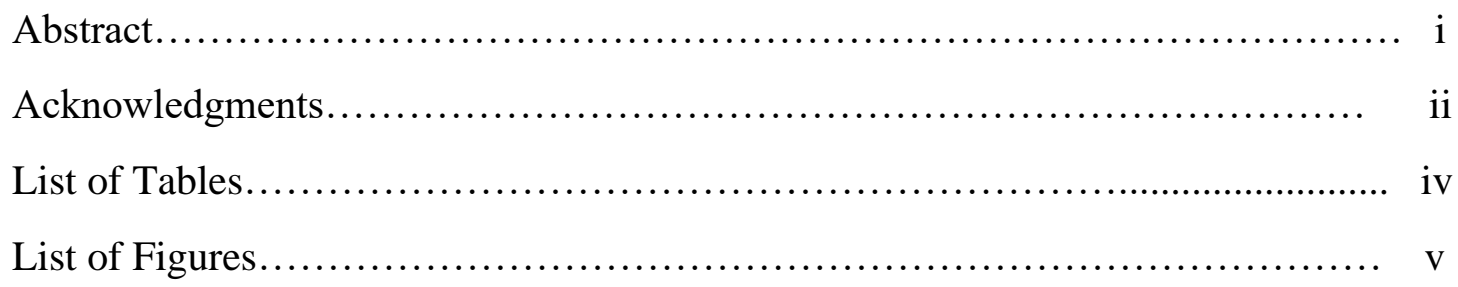

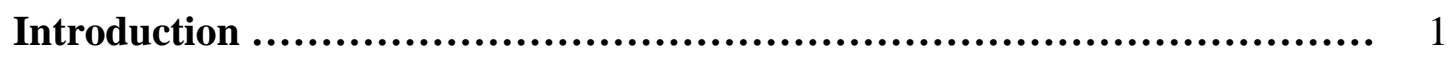

\section{Literature Review}

Early Marijuana History and Use....................................... 2

Criminalization and Efforts to Control Supply.................................. 3

Adverse Outcomes.................................................. 4

Changing Attitudes among US Population.................................. 4

Criminal Offense to Violation

Decriminalization................................................... 5

Medical Marijuana ................................................. 6

Recreational Marijuana.............................................. 7

Research on outcomes of Decriminalization............................... 8

Gaps in the Literature .................................................. 10

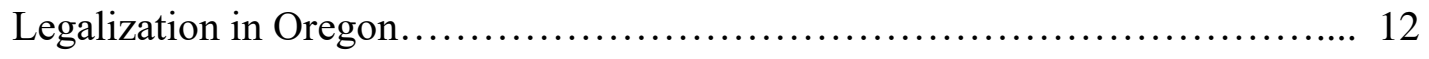

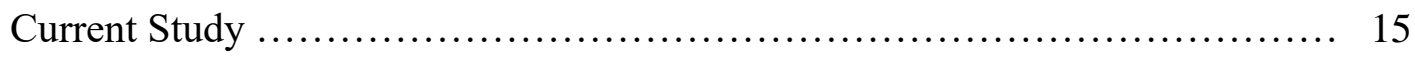

Methods.................................................................... 21

Findings

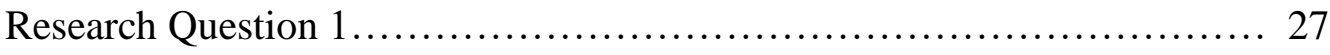

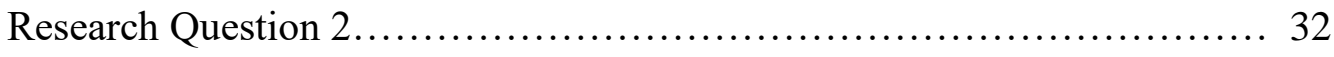

Research Question 3 .............................................. 38

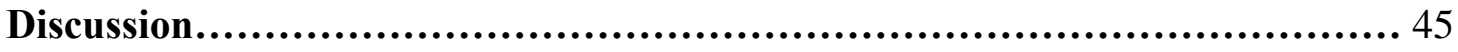

References.................................................................... 52 


\section{List of Tables}

Table 1. Agencies ............................................... 23

Table 2. ANOVA Marijuana Seizures.................................... 29

Table 3. OLS Regressions Marijuana Seizure Rates (2016 to 2019).......... 37

Table 4. OLS Regression Marijuana Seizure Rates (2016 to 2019)............. 44 


\section{List of Figures}

Figure 1. Oregon Counties........................................... 22

Figure 2. Count of Large-Scale MJ Seizures (2010 to 2019)................. 28

Figure 3. Count of Large-Scale MJ Seizures in Transport Setting (2010 to 2019).. 29

Figure 4. Count of MJ Seizures Youth under 18 (2010 to 2019)................. 30

Figure 5. Count of MJ Seizures Ages 18 to 20 (2010 to 2019)................... 31

Figure 6. Rates per 100,000 Large-Scale MJ Seizures in Transport Settings (2016 to

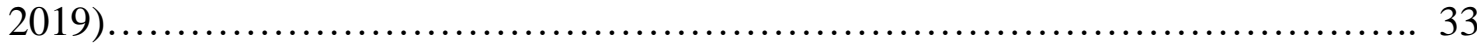

Figure 7. Rates per 100,000 MJ Seizures for Youth Under 18 (2016 to 2019)....... 34

Figure 8. Rates per 100,000 MJ Seizures for Youth Under 18 (2016 to 2019)........ 35

Figure 9. Rates per 100,000 MJ Seizures Ages 18 to 20 (2016 to 2019)........... 36

Figure 10. Rates per 100,000 Large-Scale MJ Seizures (2016 to 2019)........... 39

Figure 11. Rates per 100,000 Large-Scale MJ Seizures in a Transport Setting (2016 to

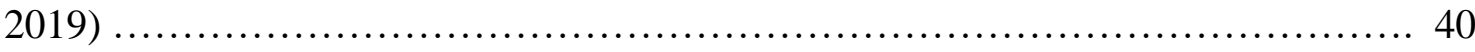

Figure 12. Rates per 100,000 MJ Seizures Youth under 18 (2016 to 2019)......... 41

Figure 13. Rates per 100,000 MJ Seizures for Ages 18 to 20 (2016 to 2019)....... 43 


\section{Introduction}

Since the early 2000s, the United States has experienced a pro-marijuana movement, with many Americans favoring legalizing recreational use of marijuana (MJ). As of mid-2020, 17 states have legalized MJ, and 23 more states have pending legislation. While this movement has mainly been occurring at the state level. The U.S. Senate introduced the MORE act in 2019, which seeks to remove marijuana from the list of scheduled substances under the Controlled Substances Act. This act signals a shift towards the acceptance of commercialization and allowance of recreational use at the federal level, further decriminalizing and abolishing the penalties associated with this substance (Harris, 2019).

After decades of a War on Drugs, MJ is slowly being decriminalized, with laws that partially or fully depenalize this substance. This shift away from criminalization is primarily due to the associated consequences of prohibition, which partially contributed to a high incarceration rate and greater racial disparities in arrests for possession of this substance. Additionally, in attempting to reduce the supply and demand of MJ, prohibition has created an immense cost within the carceral system and law enforcement efforts. Advocates for the legalization of recreational marijuana postulate that these laws could reduce racial disparities in arrests and associated costs. However, there has been opposition to this movement; politicians and law enforcement have contended that enacting these laws could produce unintended consequences such as exportation activities and an increase in black market activity leading to greater availability among youth (Pugmire, 2021; Rosato, 2021). Thus, there is a need to analyze the impact that 
Recreational Marijuana Laws (RMLs) have on marijuana-related criminal activities in states adopting this measure.

This study seeks to determine whether marijuana-related criminal activity has changed in the state of Oregon subsequent to passage of HB 123 legalizing the production, distribution, and recreational use of marijuana by people over the age of 21 . In particular, looking at differences in crime trends before and after the legalization of recreational marijuana, and the impact of the legal market on marijuana-related criminal activities such as possible exportation activities and youth access. This study specially sets out to answer the following questions: First, did large-scale marijuana seizures and incidents where MJ was seized among youth increase in Oregon after recreational MJ was legalized in 2015;2) Is there a positive relationship between the number of licenses and large-scale MJ seizures and incidents where MJ was seized among youth; and 3) Is there a positive relationship between the amount of legally produced MJ each month in Oregon and large-scale MJ seizures as well as incidents where MJ was seized among youth.

\section{Literature Review}

\section{Early MJ history and use}

Marijuana in the United States was not always a controversial topic. The hemp plant which later became known as marijuana was cultivated across US territories in the 1600s. In the 1800s, this plant that was initially harvested for its fibers began to be grown for medicinal purposes. People found that the plant was useful in suppressing pain and creating a euphoric effect. In the following decades, from the 1840s - 1850s, marijuana 
was used as an active ingredient within a variety of medications. The shift in perspective of this substance occurred in the 1900s when this plant started to be used recreationally among Mexican immigrants. In the 1920s this plant started being associated with crime and violence (Beach, 2015). This association became known as "reefer madness"; essentially it was posited that using this substance would lead the user to become aggressive and insane (Stringer et al., 2016). This led to anti-drug campaigns that altered the public perception of this substance and lead to the criminalization of this substance.

\section{Criminalization and Efforts to Control Supply}

The first laws to prohibit marijuana were passed from 1920 to the 1930 s with about 31 states passing laws that banned this substance. This was followed by the Marijuana Tax Act in 1937 that criminalized the possession of MJ, any user was fined. As time progressed, the criminalization of this substance increased; and in 1951, the Boggs Act was passed that set mandatory sentences for drug-related offenses, including marijuana. While MJ became criminalized, it did not disrupt or caused users to desist from use (Beach, 2015, United States Department Drug Enforcement Agency, 19801985). The continued use of this substance led to the War on Drugs in the 1970s that resulted in heavier law enforcement efforts to curtail the supply of MJ and other illegal substances (Alexander, 2012). In the following years, it was reported that law enforcement seized over 5.6 million pounds of MJ on the Mexico-US border, which led the federal government to allocate over 600 million dollars a year to reduce the importation of this product (The National Research Council (TNRC), 1982). While the importation of this product was a growing issue, there was also a growth in the number of 
cultivation sites across the US. In 1972, the United States Department of Agriculture estimated that there were about 5 million acres where this plant was being cultivated (TNRC, 1982). To reduce this supply the DEA created the Domestic Cannabis Eradication/Suppression Program in 1979, which provided funds to law enforcement agencies to aid in eradicating domestic grown MJ cultivation sites within their jurisdictions (United States Drug Enforcement Agency (DEA), N.D).

\section{Adverse Outcomes}

As the prohibition of MJ continued the illegality of this substance led to many adverse outcomes. Primarily the prohibition of this substance has been associated with high incarceration rates affecting minority racial groups. Those most affected have been African Americans who account for 30\% of MJ arrests while only representing 14\% of users (King et al., 2006). While the War on Drugs started in the 1970s, its impact has been most visible in the 1990s. During this decade there was an $80 \%$ increase in drug arrests across the nation, with 450,000 arrests being attributed to marijuana offenses and 79\% for MJ possession. This number continued to increase with 700,000 arrested for marijuana offenses in 2002, with $88 \%$ of arrests for possession (King et al., 2006). In 2011 it has been estimated that less than $13 \%$ of marijuana-related arrests in the United States have been for selling or manufacturing large quantities of MJ (Gramlich, 2020). Aside from the numerous arrests, the use of this substance has created a criminal enterprise that has been associated with violence due to disputes over territory or earned revenue by competitors (Goldstein, 1985). This illegal industry has been associated with the homicides of 80,000 people between 2006 and 2015 (Beittel, 2015). 


\section{Changing Attitudes among US Population}

While in the mid-1900s the perception of MJ was negative, in the late 1900s there was a change in attitude among the US population that can be pinpointed to the 1960s, in this period there was a resurgence in $\mathrm{MJ}$ use, with $\mathrm{MJ}$ viewed as a symbol of rebellion among youth (Beach, 2015). The following decades also showed heavy use of MJ, within the 1980s about $60 \%$ of teenagers had reported using MJ, and of these users, about $40 \%$ continued with regular use (DEA, 1980-1985; Monitoring the Future, 2018). About half (52\%) of Americans ages 18 and over $(\mathrm{N}=128,842,329)$ in 2017 have reported having tried marijuana at some point in their lives (Marist Poll, 2017). The experimentation and availability of this substance in earlier periods have led to a decrease in perceived harmfulness, and today many Americans view MJ to be less harmful than alcohol (Pew Research, 2014). This is visible when examining the self-reported use of MJ today, in 2019, 48.2 million Americans reported use within the past year (National Survey on Drug Use and Health, 2019). Additionally, this substance has been reported as the third most used substance after tobacco and alcohol (Caulkins, 2016). We are also seeing this change in attitudes within longitudinal public polls, from the 1990s to 2020, there has been a steady increase for those in favor of legalization of RM from 16\% to 68\% (GSS Poll, 2020; Pew Research, 2019; Gallup Poll, 2020).

\section{Criminal Offense to Violation}

Decriminalization

The first shift away from criminalization occurred in the 1970s. As the War on Drugs continued throughout the United States, a few states moved towards 
decriminalizing simple possession. Oregon was amongst one of the first states to remove jail time for the possession of small amounts of MJ. Instead, the penalty for possession of a small amount included a fine and was considered a civil infraction or minor misdemeanor. This depenalization movement varied across states, with fines ranging from $\$ 25$ to $\$ 1,000$ and each state setting an amount that was considered simple possession. Any amount over the set amount was still considered a criminal offense. Additionally, fines and punishments varied depending on age with different penalties for youth and adults. Some of these laws included mandatory drug counseling, license revocation, community service, and or rehabilitation (Plunk, 2019; Marijuana Policy Project, 2020) Currently, 14 states have passed a decriminalization law de-penalizing simple possession of MJ while still penalizing larger quantities, distribution, and cultivation of MJ, which is still a criminal offense. However, this movement was the beginning of the move towards full decriminalization of this substance.

\section{Medical Marijuana}

Alongside decriminalization, there have been efforts to legalize marijuana for medical use. Before the demonization of marijuana in the early 1920 s to 1930 s, there was some acceptance of its medicinal properties. Marijuana was associated with reducing side effects from a variety of illnesses (Grinspoon, 2005). Primarily its benefits were associated with providing relief from nausea and appetite loss, reduction in eye pressure, aiding to muscle spasms, and relief from chronic pain. Recently, it has been used to relieve panic attacks, cramps, depression, seizures, and involuntary movements (Reinarman et al, 2011). The first Medical Marijuana Laws were implemented as early as 
the 1990s with Oregon, California, and Alaska being among the first states to pass legislation allowing medical use of marijuana. This movement to legalize medical marijuana continues to grow and as of 2019, 34 states have passed laws allowing medical marijuana (MM), with 15 other states passing laws that recognize the medicinal value of this plant. These laws provided easier access for medical patients to buy legally grown marijuana from a designated licensed grower and were the first laws to allow legal production of this substance.

\section{Recreational Marijuana}

Full decriminalization of MJ did not occur till 2012 when Colorado and Washington legalized recreational use. These laws removed penalties for larger amounts of MJ possession and allowed for adults over the age of 21 to individually possess up to 28 grams of MJ within public domains. There are some variations in the allowed legal amount across RM laws. Most states that have legalized RM allow for an individual to possess between 28 grams to 70 grams in public spaces. Other variations are found in states that allow homegrown cultivations. For example, in Colorado, the amount of individual possession is greater within a private residence. As individuals are allowed up to 12 plants with 3 plants flowering at a time. All amounts beyond the set legal amount of possession whether in public or within private residences are still a criminal offense (National Organization for the Reform of Marijuana Laws, 2021). These laws primarily aimed to reduce black market activity and availability for youth through similarly commercializing marijuana to alcohol. It was posited that creating a legal market would engulf the illegal market (Gettman \& Kennedy, 2014). Additionally, through the 
regulation of this substance, it was claimed that it could create revenue that could be used for implementing programs (substance abuse programs, job placements, mental health services, etc.) or benefiting public institutions (police, schools, etc.) (Bieber, 2021; Danko, 2019). In 2021, more states are shifting towards the legalization of RM with 23 states in the process to legalize and regulate marijuana for adult use.

\section{Research on outcomes of Decriminalization}

As MJ is slowly being decriminalized, many studies have set out to analyze the impact that these laws have on arrests, crime, police resources, and their connection to the use of other substances. For instance, studies have looked at the effects of partial decriminalization and full decriminalization on arrests. A study conducted by Plunk et al. (2019) analyzing differences in arrests from 2000 to 2016 for possession of MJ across 38 states, with a sample that included 7 states with a decriminalization law, and 4 states with a legalization law found that in states that had passed a decriminalization law, there was a reduction in arrests by 131.3 per 100,000 population. In states that passed a RML, there was a greater reduction in arrests by 168.5 per 100,000 population. For youth, upon the implementation of a decriminalization law, there was a decrease in the arrests by 60 per 100,000 population, but the implementation of RM did not result in a greater decrease in arrests. A study conducted by Firth et al. (2019) in Washington also examined arrests, specifically looking at racial disparities, this study found that legalization was associated with a reduction in absolute disparities, but there were still relative disparities in MJ arrests between African Americans and White adults. However, the overall trend is that legalization and decriminalization laws have led to a reduction in arrests, but its impact 
on the jail population rates may be a modest effect. This finding was found in a study conducted by Stanton et al. (2020) that examined 38 county jails within Washington.

The studies that have analyzed crime have seen differences depending on the enacted laws. MMLs have been associated with a reduction in certain types of crime. While RMLs have been associated with having a minor to no impact on crime or reductions across some categories of crime. For example, a study conducted by Morris et al (2014) analyzing US state panel data from 1990 - 2006 and a study conducted by Shepard et al. (2016) looking at differences in property crime, violent crime, and drug arrests before and after the implementation of a MML within 11 western states found an association between these laws and a reduction in violent crimes (e.g., Assault, Homicide, Rape, Robbery). These reductions were attributed to a decrease in cartel activities as MMLs opened an avenue to procure MJ. Similarly, a study conducted by Dragone et al. (2019) looking at RM in Washington comparing their crimes to Oregon (pre-legalization of RM) found a reduction in rapes and property crimes. The authors posited that these reductions could be attributed to few factors such as the psychotropic effects of MJ; possible substitution away from violence-inducing substances (meth, heroin, etc), the reallocation of police efforts to other types of offenses, and a reduced role of criminals within the marijuana market. One study that found a slightly different outcome was conducted by Lu et al (2019) analyzing crime trends in Colorado and Washington from 1996 to 2016, within this study they found a short-term increase in violent and property crime rates after the opening of retail shops. It also posited that RM has had only a minimal to no effect on major crime rates within these locales. A study 
that found a similar trend was conducted by Aydelotte et al (2019) analyzing fatal crashes in Colorado and Washington after the implementation of RM. In this study, there was an increase in fatal crashes corresponding to the opening of retail shops, but overall, the impact was not statistically significant.

One of the potential benefits that have been associated with RMLs is the ability for police to redirect substantial resources away from $\mathrm{MJ}$ and onto other public safety topics. In Washington and Colorado legalization of MJ was associated with an increase in clearance rates for violent and property crimes (Makin et al, 2018). Additionally, in Washington, the passing of RM has been associated with an increase in welfare calls, but other calls for service (traffic accidents, alcohol offenses, simple assaults, burglary, disorderly conduct, domestic disturbances, drug offenses, driving under the influences, noise complaints or thefts) have not changed (Makin et al, 2020).

When it comes to assessing the association between MJ and other substances, most of the studies have viewed this association in connection to MMLs. A study conducted by Anderson et al (2013) found a reduction in alcohol consumption in states that had passed a MML, with a greater impact among youth. Similarly, an examination of three states with a MML saw a decrease in annual opioid overdoses by $25 \%$ when compared to ten states without this law (Bachhuber, 2014).

\section{Gaps in the Literature}

While the current literature regarding MJ laws has been substantial some areas have not been clearly studied. For example, fewer studies have been conducted across other states that have legalized RM, most of the current studies focus on Washington and 
Colorado. Additionally, fewer studies have examined the impact of RM within Oregon. A study that was conducted in Oregon analyzing crime data from 2007 to 2017, found an increase in certain types of crimes (burglary, motor vehicle theft, aggravated assault, and larceny) occurring after legalization. This study did further analyses leading to an examination of a post-period of legalization (2016 to 2019), while some crime categories were still associated with a significant increase post-legalization, aggravated assault was reduced to non-significant. The author posited that the increase in these crimes could be attributed to the presence of a black market (Wu et al., 2020). This is an area of the literature that very few studies have attempted to examine. One study that looked at black-market activity within the context of legalization was conducted by Song (2019) looking at Washington. This study found that within Washington the regulation intensity influenced marijuana crime rates. Initially, the implementation of intensive regulations led to a small decrease in marijuana crime rates, but over time there has been a steady increase that is possibly associated with legal business owners choosing to operate in the black market. These studies posit the idea that the legalization and regulation of MJ may influence marijuana crime rates.

Another area where research is limited is the impact of certain features of legalization or commercialization on crime. For example, Contreras and colleagues (2017) looked at dispensaries (retail shops) and their influence on crime in nearby neighborhoods. This study found an increase in crime after the opening of this shop. This study speaks to the idea that legalization may have some criminogenic features and legal businesses may have an impact on crime rates. 
There have also been mixed findings of the impact of RMLs on marijuana use among youth. For example, in Washington legalization was associated with an increase in adolescent use, whereas Colorado did not see an increase in use among youth (Cerda et al, 2017). This is an area that could be benefited by further exploration, as more consistency has been found with MMLs that have been associated with no significant effect on marijuana use among youth (Harper et al., 2012; Wall et al., 2016; LynneLandsman et al., 2013; Anderson et al., 2011). RMLs could potentially provide greater access to youth than previous laws (MMLs) and this could be related to the implementation of these laws, as there are variations from state to state.

Lastly, from an exhaustive search of the literature, no studies were found exploring the impact of the regulatory framework in states where MJ has been legalized. Fewer studies have set out to explore the impact of regulatory features such as the marketplace (number of licensed businesses) or the impact of legally produced MJ. This is an area that needs further exploration, and the current study aims to add to this gap in the literature through the examination of Oregon's implementation of the commercialization of $\mathrm{MJ}$ and its impact on possible exportation activities as well as access among youth.

\section{Legalization of RM in Oregon}

The effort to legalize RM first started in 2012, when Measure 80 was set to be voted on via ballot. This measure attempted to legalize RM within Oregon, with no set limit for possession or cultivation of MJ and was rejected with 55\% of Oregonians voting against this measure (Oregonian, 2012). The second attempt occurred in 2014 with 
Measure 91, which had more substance and set more guidelines for the user and commercialization of MJ. Advocates argued that this measure would reduce the financial cost of arresting and citing marijuana users. In addition, it would limit the availability of MJ for youth by diminishing the black market (Ballotpedia, 2014).

In 2015, Measure 91 passed with 56\% of Oregonians in favor, this measure decriminalized the use and allowed for individuals to possess larger quantities of MJ setting limits by domain. In public spaces, an adult over the age of 21 can individually possess under 28 grams of useable MJ and below 226 grams within a private residence. While this measure was passed in July 2015, the opening of marijuana retail shops did not occur till October 2016. However, in efforts to diminish the black market by reducing its business, this measure gave temporary permission for medical dispensaries to sell to adults over the age of 21(Oregon-Idaho Intensity Drug Trafficking Area (OIDTA), 2018). While this bill set the allowed amount of possession, its taxation, and commission, it failed to set certain guidelines for the number of licensees per county, quantity of production, and tracking of home-grown cultivations. These are areas that spurred concern, as the number of applicants greatly exceeded the forecasted amount. Initially, Oregon expected to distribute approximately 826 licenses from 2015 to 2017 . Yet, by October 2018, the Oregon Liquor Control Commission (OLCC) had approved 4,389 licenses with more than half of these licenses corresponding to producers and processors. Less than half of approved licenses were for wholesalers or retail shops (Oregon Secretary of State (OSOS), 2019; OLCC, 2021). This overwhelming number of licenses led to an inability to conduct compliance checks; the ratio of inspectors is roughly 1:88 
and within the year of 2018, the OLCC had only been able to inspect about $32 \%$ of all licensed producers. This has left the majority of the MJ inventory unchecked which can be problematic as there has been a mass production of $\mathrm{MJ}$ that has flooded the legal market beginning in 2017. In 2019 the estimated unsold inventory was about 760,000 lbs. of $\mathrm{MJ}$ that was projected to be able to sustain the current user base for 6 years (OLCC, 2019). However, marijuana has a short-shelf life with usable MJ estimated to expire within a year, and derivatives extending this shelf-life to about 2 years (Washburn, 2018).

The combination of a mass number of licensees, overproduction, and a valued product across the United States, has created concern at both the national and state level. In an op-ed, Billy J. Williams, the United States Attorney representing the state of Oregon - noted concerns about recent trends of MJ seizures and possible exportation activities occurring within Oregon primarily due to the overproduction of marijuana that is intended for legal distribution (Williams, 2018). Possible exportation activities have also been reported within Deschutes County, within this county, there has been an increase in MJ drug seizures occurring from 2016 to 2018 (Henning \& Stewart, 2019). Similarly, in 2017, the Oregon State police reported a high per capita diversion rate of 13 events or $3971 \mathrm{bs}$ per 100,000 residents when compared to Washington, which has a per capita rate of 7 events or $214 \mathrm{lbs}$. per 100,000 residents, the police associated the high diversion rate for Oregon with the occurring overproduction. These rates were calculated using data accessed through the El Paso Intelligence Center (EPIC) from 2006 to 2016 (The Oregon State Police, 2017). 


\section{Current Study}

Before legalization, Oregon had been known for producing top-quality MJ due to the topography within this region, which creates an environment that is ideal for growing outdoor MJ (LeafBuyer, 2017). In recent years, illegal grow sites on public lands in Oregon have been linked to unlicensed growers (cartels), and in 2016, 26,500 plants were found (OIHITA, 2018). While legalization is meant to suppress this type of illegal activity, it may not completely diminish it (The Washington Institute, 2019). Some of this illegal activity can be sustained as there are still customers to cater to, for example, youth or young adults under the age of 21. Additionally, there are still areas in Oregon that have opted out of commercialization (OLCC, 2021) these areas may still have customers depending on their distance to the nearest town where MJ businesses are allowed (Hausfeld, 2016; Stewart, 2018; Walsh, 2020).

On top of the illegal market, there is also a growing legal market. To create a strong market, Oregon chose a three-tier system, splitting up commercialization across multiple segments. This system has led to the creation of a competitive market, where businesses are competing to survive. Associated with the legal market are also fees, application renewals that occur annually, and required surveillance equipment. While this industry is costly for its entrepreneurs, this industry is perceived as profitable and viewed as sustainable due to the loyal consumer base (OLCC, 2019). However, due to a large number of competitors, businesses may be struggling to stay afloat (Song, 2019).

While the competitive market within the legal and illegal market may be conducive to crime, the overproduction of $\mathrm{MJ}$, has created a marketplace that is unstable 
leading to a drop in prices (Whelman et al., 2003; OLCC, 2019). This price drop may entice users to purchase from legal businesses but creates an unprofitable market for business owners (The Washington Institute, 2019). To create a profitable market an equilibrium needs to be created between supply and demand (Whelman et al., 2003). When there is an excess amount of product it creates a market where prices are low and less profitable affecting businesses. On the other hand, when demand isn't met this creates a marketplace where prices are high affecting consumers' and their willingness to buy from this market. Since the legalization of RM in Oregon, the marijuana market had experienced a decrease in profit and prices across each commercialization segment (shops, wholesalers, producers, and processors), leading to less revenue being made than at the start of legalization (OLCC, 2021). This drop in prices is most visible within retail shops with average prices decreasing from $\$ 10.50$ per gram to $\$ 5$ per gram. The current price may reduce profitability within the black market as the main enticement is the low prices (OLCC, 2021; Perrault et al., 2019). On the other hand, within the legal industry, the glut in product leaves producers/processors in a dire situation due to the inability to sell the product. To stay afloat some of these businesses could potentially partially operate within the illegal market to offset the cost of compliance (Song, 2019). Additionally, the strain in oversight may reduce the risk associated with diverting MJ to the black market (OSOS, 2019; The Washington Institute, 2019).

The combination of all these competitors both within the illegal market and the legal market along with overproduction and price drops may limit the number of customers within the state as well as profit. As most consumers prefer legal products 
(Aumlung et al., 2018). While it may be difficult to measure the amount of MJ within the state, a Portland-based consulting firm ECONorthwest has estimated that only $30 \%$ of the market is visible within the legal market. This estimate was established by analyzing the medical marijuana market examining the number of allowed plants, the number of patients, and MJ that had disappeared or was unaccounted for (The Oregon State Police, 2017; The Mail Tribune, 2016). With the inundation in the legal market and illegal grow sites adding to this base of production with limited customers in-state, it may produce incentives within both markets to divert product out of state (OLCC, 2019; OHIDTA, 2018; The Washington Institute, 2019). As there are still states under prohibition where dealers can set a higher price point that is not only profitable but also enough to offset the risk of transporting.

While the implementation of the commercialization of RM has spurred concern there have also been concerns about the passing of the law itself. A study conducted by Henning and Stewart (2021) surveying 301 officers/deputies in Oregon reported perceived increases in marijuana-related offenses within the past 3 years. For example, $90 \%$ of 301 officers/deputies have stated that there has been an increase in illegal shipping or transporting of MJ out of state. In addition, $87.9 \%$ of these officers/deputies have reported that young people using/possessing MJ has "increased a lot". From the perspective of law enforcement in Oregon, officers/deputies perceive that the passing of RM has led to an increase in exportation activities and distribution to youth.

To assess the current market climate and the impact of legalization, the current study uses proxy measures to examine possible exportation activities and illegal 
marijuana distribution. While we do not have accurate data on MJ that is exported out of state, it is possible to analyze changes in large-scale seizures (amount of possession that is illegal) of MJ over time. To examine illegal marijuana distribution this study uses the proxy of arrest/citations of youth and young adults under the age of 21 where any amount of MJ is seized, as this group is not able to purchase from the legal market. To analyze the current market climate and available product, the legal harvest data can be used as a proxy measure to account for how much MJ is available within the state throughout the year. While we cannot account for illegal businesses, we can account for the competitive market through the proxy measure of the number of licensed businesses, which has kept increasing since the start of commercialization. Additionally, we include a proxy measure for police proactivity - to control for how active law enforcement is when it comes to drug-specific crimes, using the count for incidents of illegal substances (heroin and meth). As law enforcement has stated that the current legislation makes it difficult to enforce marijuana-related offenses. However, law enforcement in Oregon has reported seeing increases in exportation activities and youth possession (Henning \& Stewart, 2021) creating a problematic dilemma as marijuana-related incidents could decrease due to police inactivity.

To summarize, this study sets out to examine Oregon's approach to legalization and its impact on marijuana-related offenses that are still illegal under Oregon's law. Research on this topic remains limited, necessitating the current study. This study aims to add to the literature by analyzing the impact that the commercialization of MJ may have on possible exportation activities and distribution to youth. Using elements of 
commercialization such as the amount of legally grown marijuana and the number of licensed businesses. This study sets out to answer the following questions:

1) Did the large-scale MJ seizures and incidents where MJ was seized among youth increase in Oregon after recreational MJ was legalized in 2015?

$\mathrm{H}$ : We should see an increase in MJ-related offenses after legalization.

Since the passing of Measure 91, law enforcement in Oregon has reported perceived increases in marijuana-related incidents in the years following legalization (Henning \& Stewart, 2021). Additionally, politicians and law enforcement outside of Oregon have asserted that the passing of RM could lead to unintended consequences such as exportation activities or distribution to youth (Pugmire, 2021; Rosato, 2021). In Deschutes County in Oregon, there has been a reported increase in charges for minor possession from 73 incidents in 2015 to 167 incidents in 2018. This county has also reported increases in unlawful import/export of MJ with 2 incidents in 2016 to 7 incidents in 2018 (Henning \& Stewart, 2019). From the anecdotal accounts and reported increases in marijuana-related offenses, we hypothesize that we should see an increase in MJrelated offenses after legalization.

2) Did large-scale MJ seizures and incidents where MJ was seized among youth increase in Oregon as the number of licensed businesses increased?

$\mathrm{H}$ : We should see an increase in MJ-related offenses as the number of licensed businesses goes up. 
Initially, Oregon set no limit for the number of available licenses and within months the OLCC received more applications than what they initially forecasted based on a projection of approved licenses in Washington and Colorado (OSOS, 2019). This led to a massive number of MJ businesses opening across Oregon within a short time frame and this number has kept increasing since. As the number of licensed businesses increases it creates a competitive market where businesses are battling to survive within the industry and with illegal businesses. This type of market produces a strain in oversight in the legal market and a reduction in profitability across the state (Whelman et al., 2003; OSOS, 2019; OHDITA, 2018). Additionally, this industry comes with a high cost that may lead some businesses to operate partially within the illegal market (Song, 2019). Thus, we hypothesize that as the competitors increase, we will see an increase in large-scale seizures and incidents where MJ is seized among youth.

3) Is there a positive relationship between the amount of legally MJ produced each month in Oregon and the number of large-scale MJ seizures and incidents where MJ was seized among youth?

$\mathrm{H}$ : We should see a positive association between the amount of legally produced MJ and the number of MJ-related offenses.

Oregon's unique problem of overproduction of MJ has spurred concerns at both the state and national levels. There have been reported increases in MJ seizures occurring on highways heading out of state and perceived increases in youth possession of MJ that have been attributed to the overproduction of MJ (Henning \& Stewart, 2021; The Oregon State Police, 2017; Henning \& Stewart, 2019; OHDITA, 2018; Williams, 2018). 
Additionally, this overproduction has been projected to be able to sustain the current user base for 6 years, however, this type of product has a very short shelf-life (OLCC, 2019; Washburn, 2018). With the inundation visible within the legal market and the addition of illegal production, competitors may need to found outlets for excess products (The Oregon State Police, 2017; OLCC, 2019). Thus, we hypothesize that we should see a positive association between the amount of legally produced MJ and large-scale seizures as well as incidents where MJ was seized among youth.

\section{Methods}

Two major data sources were used in this study. First, incidents from 2010 to 2019 were accessed through the National Incidence-Based Reporting System (NIBRS) that contains incident-level data reported by participating law enforcement agencies across the United States. Participating law enforcement agencies reported on over 52 offenses. These data include date and time, victim types, relationships of victims to the offender, demographic details, location data, property descriptions, drug types and quantities, an offender's suspected use of drugs or alcohol, involvement of gang activity, and whether offenses were cleared. For this study, multiple offenses were analyzed looking for a connection to MJ seized and drug seizures including any type of illegal substance were retrieved.

The second major data source was from the Oregon Liquor Control Commission (OLCC), an organization that oversees Oregon marijuana businesses and provides statistics for the marijuana market. From their website, legal harvests data were accessible through a public dashboard. Licensing data were available through a public 
records request; the data provided by this agency ranged from 2016 to 2019. The harvest data included the wet weight of the legal harvest for each county. The wet weight was defined as the full weight of the marijuana plant before being dried for sale. The data for licensees included any marijuana license, categorized as producers, processors, wholesalers, and retailers. Each category represents a segment in the commercialization of MJ. That is, producers grow marijuana and processors create extracts or other substances. Wholesalers purchase the harvested marijuana or products and sell the product to the retail market. Using these data, monthly totals were aggregated for months starting in January 2010 to December 2019.

\section{Sample}

The final sample was derived from NIBRS compliant Oregon law enforcement agencies that reported their offense data to this system. In as early as $2010,33.9 \%(\mathrm{~N}=59)$ had reported their offenses to NIBRS, while $66.1 \%(\mathrm{~N}=115)$ of agencies did not. Of this sub-sample of agencies that did report to NIBRS, the main criterion for inclusion in this study was that the agency had to have contributed data to NIBRS for all years from 2010 to 2019. Agencies that started midway or left within the study period were excluded. Additionally, agencies that were missing one year of data or more were excluded. This left 41 agencies (Table 1) across 13 counties (Figure 1). This sub-sample is representative of about $35 \%$ of the population within Oregon. 


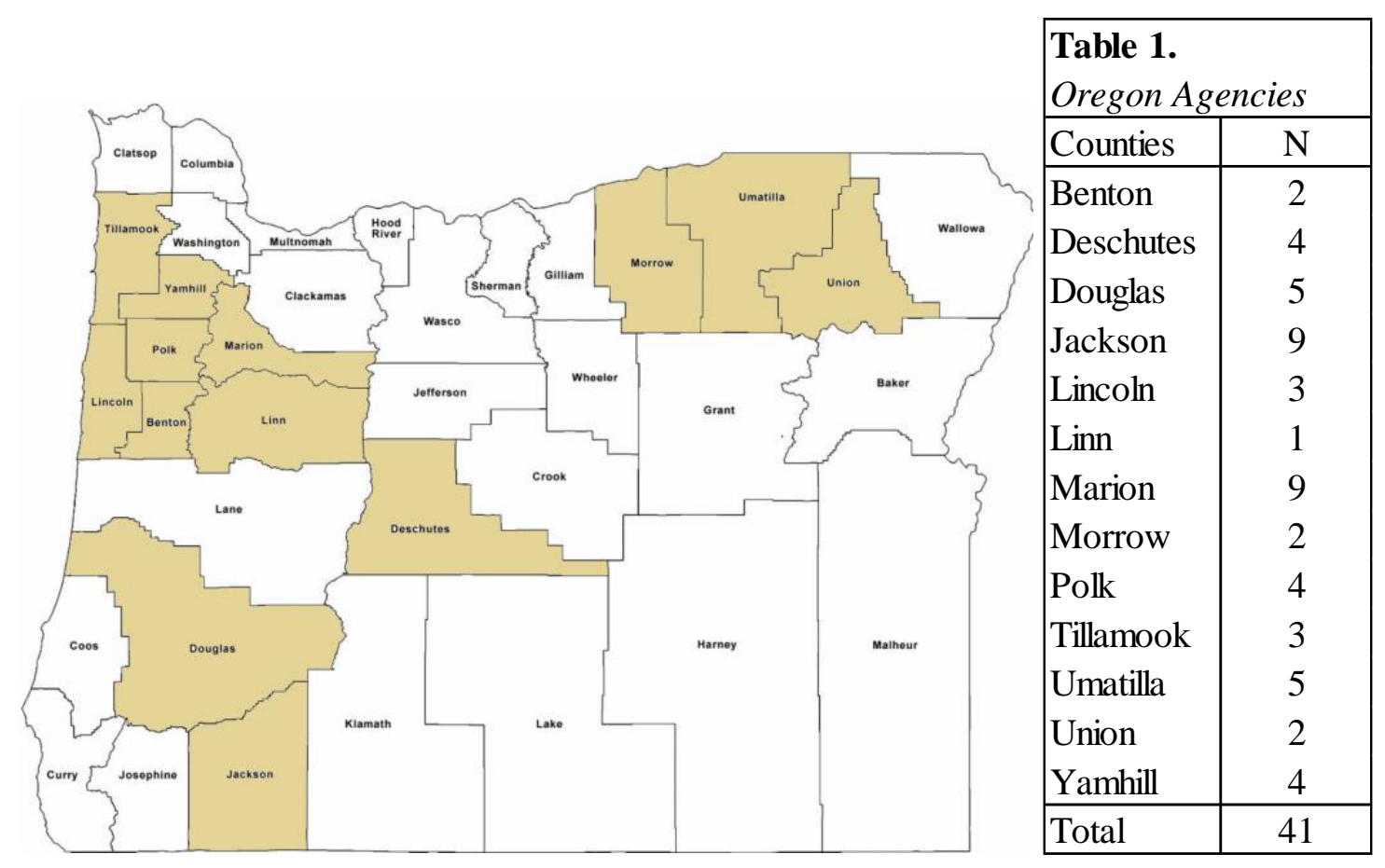

Figure 1. Oregon Counties

\section{Independent variables}

Three independent variables were coded for this study.

Legalization of $R M$ - a dichotomous variable was coded to identify whether each month between 2010 and 2019 was before (0) or after (1) RM was legalized in the state. All months preceding July 2015 were coded 0 and all months from this date were coded 1 .

Licensed Producers \& Processors - OLCC data was used to determine the number of active MJ producers/processor licenses for each given year/month. That is, from 2016 to 2019, a license was deemed active based on its status on the $15^{\text {th }}$ of the month. This variable was coded to include only licenses that resided within the counties where incident data is available. 
Legal Marijuana Harvest - OLCC data that is self-reported by producers (growers) through the Metrc Tracking System was used to determine the monthly wet weight of production from 2016 to 2019 . Only harvest data for each county where incident data are available were included. This variable was transformed using the natural log to create a normal distribution.

\section{Dependent variables}

Four dependent variables were coded for the present study.

Large-Scale MJ Seizures - NIBRS data were used to document the number of MJ seizures involving more than 226 grams for each participating agency. These data were aggregated across all agencies resulting in a total for each given year/month from 2010 to 2019. This amount (more than 226 grams) was chosen as this is above the legal amount of possession.

Large-Scale MJ Seizures in Transport Settings - NIBRS data were used to document the number of MJ seizures involving more than 226 grams for incidents within a transport setting (highway/road/alley/sidewalk and air/bus/train terminals) for each participating agency. These data were aggregated across all agencies resulting in a total for each given year/month from 2010 to 2019 . The objective here was to indirectly quantify potential exports heading out of state.

MJ Seizures Youth under 18 - NIBRS data were used to document the number of incidents involving any amount of MJ seized for youth under 18 for each participating 
agency. These data were aggregated across all agencies resulting in a total for each given year/month from 2010 to 2019.

MJ Seizures Ages 18 to 20 - NIBRS data were used to document the number of incidents involving any amount of MJ seized for young adults ages 18 to 20 for each participating agency. These data were aggregated across all agencies resulting in a total for each given year/month from 2010 to 2019.

Once again, youth under the age of 18 and young adults ages 18 to 20 are not legally allowed to possess MJ under Oregon's law. As such, this metric is derived to assess possible illegal distribution to youth.

\section{Control Variables}

The present study controlled for population and police proactivity. As decreases in the number of incidents could be affected by population changes throughout the years, we controlled for the population within these counties. Additionally, we include a proxy measure for police proactivity as a basis for how active police were during the periods assessed.

County Population - Population estimates were documented using the Population Research Center at Portland State University. County statistics were aggregated for all the counties where participating agencies reside, for each given year/month from 2010 to 2019. 
Youth Population - Population estimates for youth were documented using the American Community Survey. A total was generated for all the counties where participating agencies reside, for each given year/month from 2010 to 2019.

Crime Rates - Population estimates were used to standardize the number of incidents per 100,000 residents for each dependent variable (large-scale MJ seizures, large-scale MJ seizures in a transport setting, MJ seized for youth under the age of 18 , and MJ seized for ages 18 to 20) for the given year/month from 2010 to 2019. These variables were coded to account for population changes.

Police Proactivity - NIBRS data were used to document the number of seizures involving Heroin and Meth for each participating agency. These data were aggregated across all agencies resulting in a total for each year/month from 2010 to 2019. This variable was coded to account for how active police were when it came to drug-specific crimes.

\section{Analytical Plan}

These data are analyzed in two parts. First, we analyzed differences in the number of incidents and rates per 100,000 for each dependent variable pre-and post-legalization using a two-way analysis of variance (ANOVA). Secondly, these data were used to analyze the legal market, starting at the point of approved licenses, and when the first harvest was reported. To assess the impact of the legal market on each dependent variable, we ran ordinary least square regressions (OLS) examining the impact of the number of licensed businesses (producers/processors) on the rates of incidents per 100,000 (producers/processors) for each dependent variable while controlling for police 
proactivity. To assess the impact of MJ production on the rates per 100,000 for the four dependent variables, we ran OLS regressions including the amount of MJ that was produced monthly while controlling for police proactivity.

\section{Findings}

RQ 1 - Did the large-scale seizures and incidents where MJ was seized among youth increase in Oregon after recreational marijuana was legalized in $2015 ?$

H: We should see an increase in large-scale MJ seizures and incidents where MJ was seized among youth after legalization.

Recreational marijuana was legalized in July 2015; with the passing of this legislation, MJ was decriminalized allowing for adults over the age of 21 to possess under 226 grams (half a pound) within their home. Any amount over this quantity and youth possession is still prohibited. This law was meant to reduce the illegal activities associated with prohibition and reduce the availability of marijuana among youth.

However, there were also concerns about whether legalization would do the opposite and increase these illegal activities, these concerns were expressed by law enforcement and politicians (Henning \& Stewart, 2019; Pugmire, 2021; Rosato, 2021). For the first part of these analyses, we analyze the number of incidents before and after legalization within the targeted counties where crime data is available. To check for accuracy of the two-way ANOVA we also conducted an independent t-test and no differences were found. 


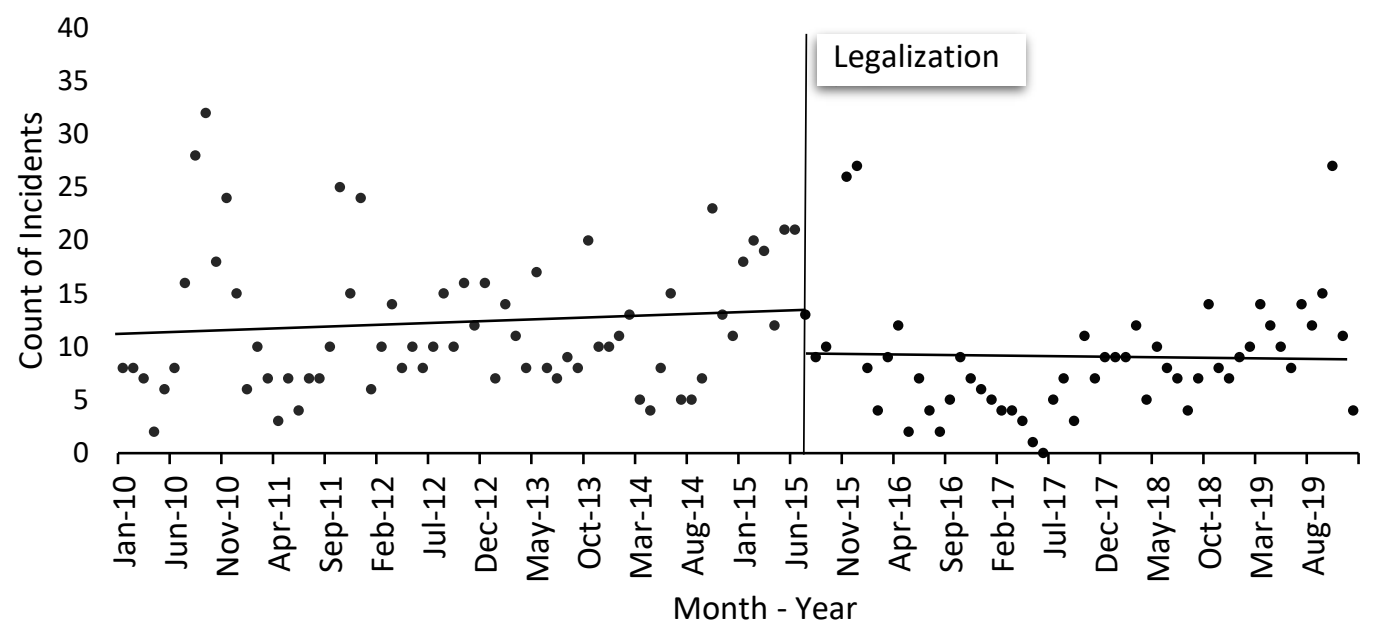

Figure 2. Count of Large-Scale MJ Seizures (2010 to 2019)

Before legalization, the trend of incidents for large-scale MJ seizures involving more than 226 grams increased and the incidents were sporadic throughout the months. Since the point of legalization, the trend in seizures has remained stable (Figure 1). When averaging these counts, it appears that with the passing of Measure 91 there has been a decrease in these incidents, with an average number of 12 incidents before legalization and 9.3 incidents after (Table 2). These findings are not consistent with the hypothesis that large-scale seizures involving more than 226 grams would increase post-legalization of RM. Instead, we have found just the opposite, that seizures involving more than 226 grams have decreased. One limitation of this analysis is that there may have been population changes in these counties that could account for these findings. If the population decreased, there might be fewer offenses of this nature. To address this, we standardized the number of incidents to account for population changes. When this is accounted for, we are seeing the same relationship. On average there was a rate of .09 
incidents per 100,000 residents before and .06 incidents per 100,000 residents after legalization (Table 2)

Table 2.

ANOVA Marijuana Seizures (2010 - 2019)

\begin{tabular}{lrrrrrrr}
\hline & \multicolumn{3}{c}{ Pre } & \multicolumn{3}{c}{ Post } \\
\hline & $\mathrm{N}$ & $\mathrm{M}$ & \multicolumn{1}{c}{ SD } & \multicolumn{1}{c}{ N } & \multicolumn{1}{c}{ M } & \multicolumn{1}{c}{ SD } & \multicolumn{1}{c}{ F } \\
\hline Large Scale MJ Seizures* & 66 & 12.0 & 6.5 & 54 & 9.3 & 6.7 & 5.192 \\
Rate of Large-Scale MJ Seizures* & 66 & 0.1 & 0.0 & 54 & 0.1 & 0.0 & 7.582 \\
Large-Scale MJ Seizures in Transport Setting & 66 & 3.2 & 2.7 & 54 & 3.1 & 2.6 & 0.007 \\
Rate of Large-Scale MJ Seizures in Transport Setting & 66 & 0.0 & 0.0 & 54 & 0.0 & 0.0 & 0.171 \\
MJ Seizures Youth Under 18** & 66 & 86.7 & 28.6 & 54 & 56.9 & 23.7 & 37.643 \\
Rate of MJ Seizures Youth under 18** & 66 & 60.0 & 19.6 & 54 & 41.0 & 16.8 & 31.662 \\
MJ Seizures Ages 18 to 20** & 66 & 61.4 & 21.8 & 54 & 23.2 & 10.2 & 143.308 \\
Rate of MJ Seizures Ages 18 to 20** & 66 & 101.4 & 36.8 & 54 & 38.5 & 16.7 & 134.732 \\
\hline
\end{tabular}

$\mathrm{P}<.05 * \mathrm{P}<.01 * * \mathrm{P}<.001 * * *$

Rate - per 100,000 residents

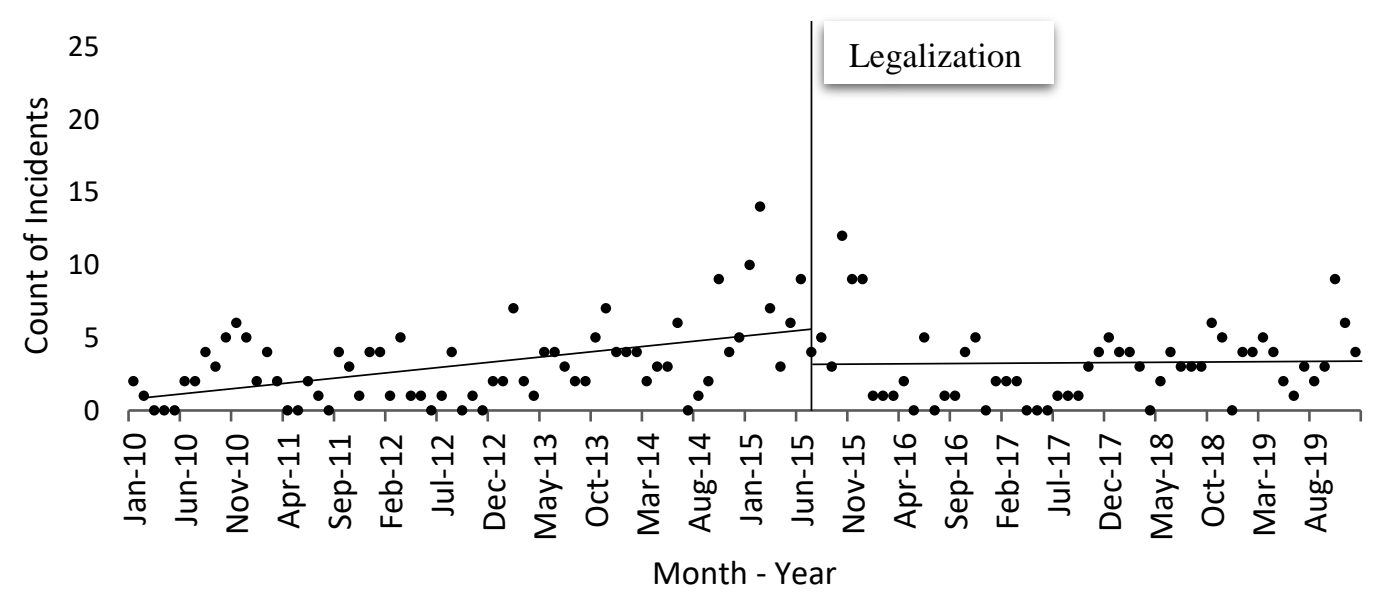

Figure 3. Count of Large-Scale MJ Seizures in Transport Setting (2010 to 2019) 
For large-scale MJ seizures in a transport setting, we see a similar trend as incidents involving large-scale MJ seizures where these incidents were increasing before legalization. Upon legalization we see a different trend, the trend in large-scale MJ seizures in transport setting is stable; it has neither increased nor decreased. It must also be noted that pre-legalization the number of incidents is particularly high near the point of legalization and upon legalization, the number of incidents remains high but decrease before January 2016 (Figure 3). While the trend in MJ seizures seems to differ pre- and post-legalization when we analyze the averages before and after legalization there is no statistically significant change (Table 2). The average number of incidents before legalization was 3.2 incidents and 3.1 incidents after. This is also the case when examining rates. Before legalization there was a rate of .02 incidents per 100,000 residents, this is also the average after legalization (Table 2). Legalization appears to have a minor impact on this type of offense.

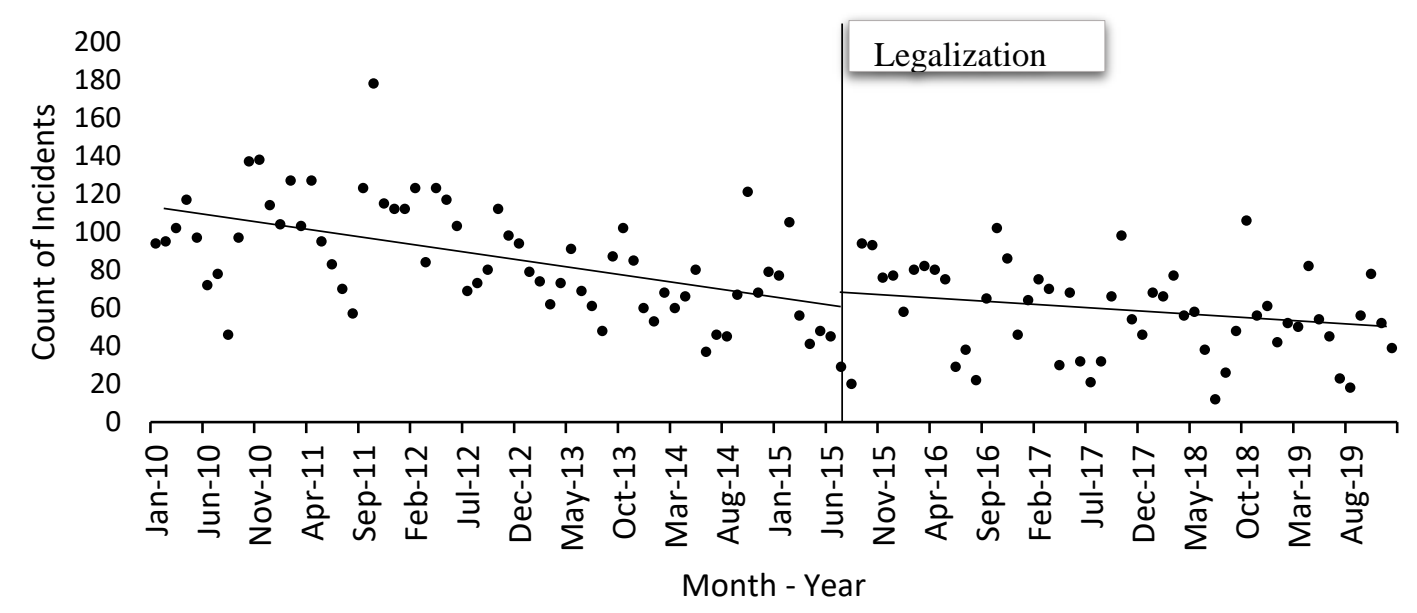

Figure 4. Count of MJ Seizures Youth under 18 (2010 to 2019) 
In analyzing incidents where MJ was seized for youth under the age of 18, prelegalization there is a decreasing trend (Figure 3). After legalization, the trend is still decreasing but at a less drastic rate (Figure 3). Nonetheless, in averaging the counts, prelegalization there is a decrease from 86.7 incidents to 56.8 incidents after. In accounting for population changes within these counties, there is also a decrease from 60.1 incidents per 100,000 residents to 41.1 incidents per 100,000 residents after legalization (Table 2). Contrary to our hypothesis, MJ seizures for youth under the age of 18 did not increase after legalization.

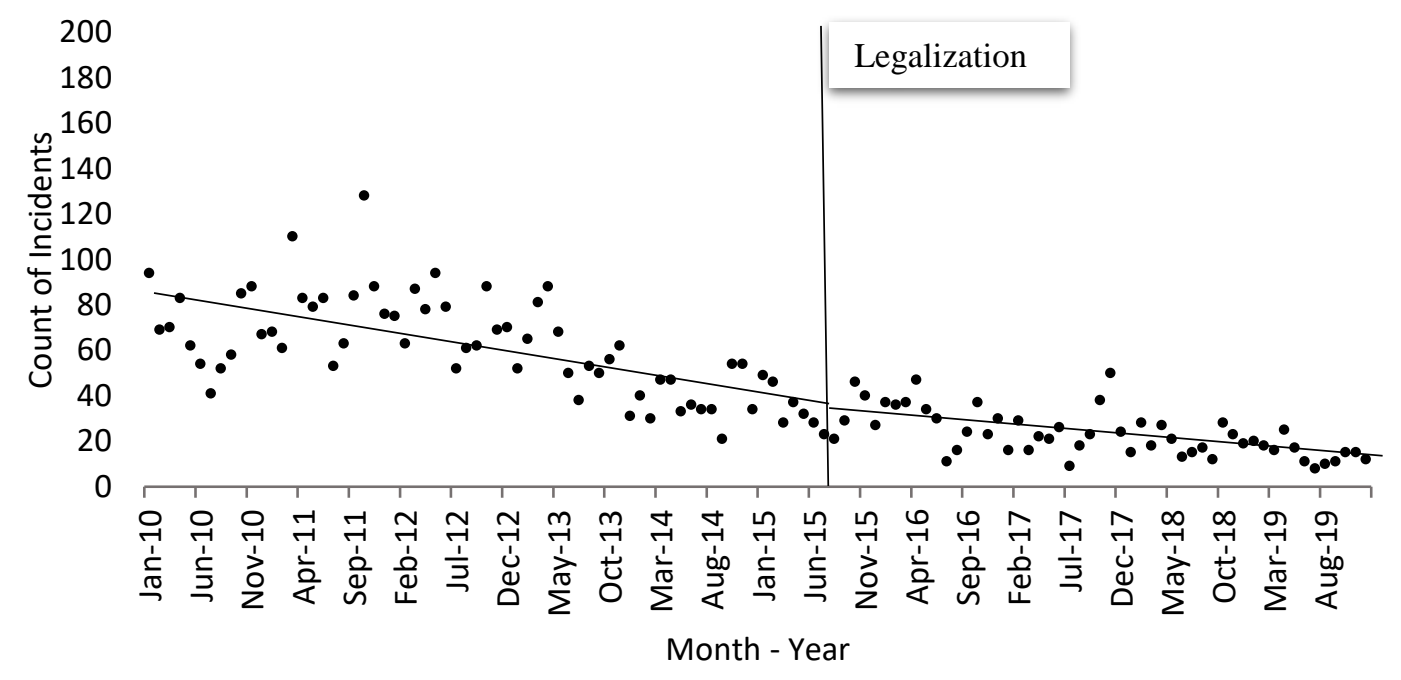

Figure 5. Count of MJ Seizures Ages 18 to 20 (2010 to 2019)

The only offense that has seen a drastic decrease in the number of incidents has been incidents where MJ was seized involving young adults ages 18 to 20 . The trend in these incidents had been decreasing before legalization, and legalization may have caused these incidents to decrease at a sharper rate. On average before legalization, 61.4 
incidents were occurring and after legalization, this decreased to 23.2 incidents. When we account for population changes this decrease is a bit more prominent with a rate of 101.4 incidents per 100,000 residents before to 38.5 incidents per 100,000 residents after (Table 2). These findings are not consistent with our hypothesis, upon legalization we are not seeing an increase in the number of MJ seizures involving young adults ages 18 to 20 .

RQ 2 -Is there a positive relationship between the number of licenses and marijuanarelated offenses?

H: We should see an increase in MJ-related offenses as the number of licensed businesses increases.

The legalization of RM marijuana was passed in July 2015, but the commercialization of this substance did not begin till May 2016. In May the first MJ licenses for producers and processors were approved, this allowed for production to begin legally. For the following analyses, we will be examining the relationship between the growth in producer/processor licenses and crime rates. As noted previously, the number of incidents could be affected due to population changes, to resolve this, we chose to examine crime rates in comparison to growth in licenses. The impact will be assessed using OLS regressions while controlling for police proactivity. 


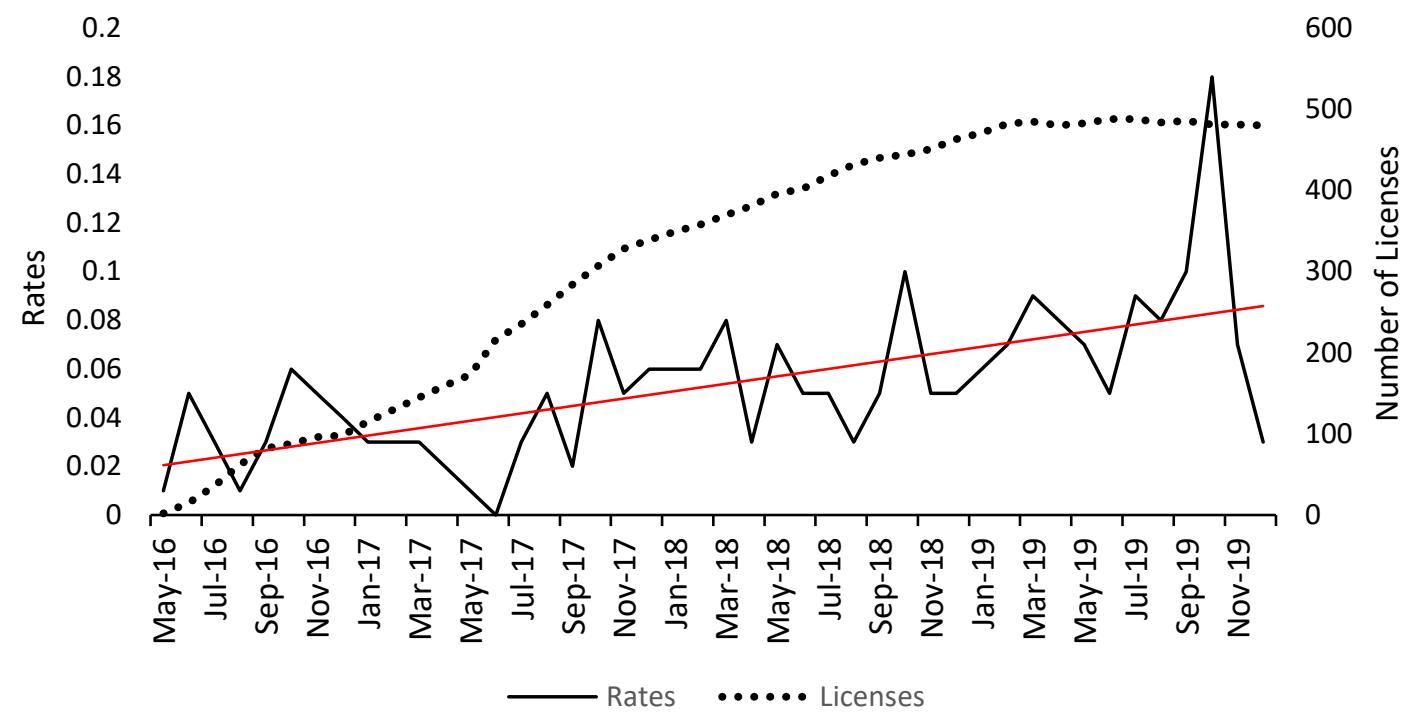

Figure 6. Rates per 100,000 Large-Scale Marijuana Seizures (2016 to 2019)

For these analyses, we wanted to see whether crime rates would rise as the number of licensed businesses increased. To better understand this relationship, we chose to connect the points for rates across the months, this provides a visual for the relationship in increases or decreases across the months and years. In conducting this analysis, we are seeing a different relationship than what we saw prior when examining the number of incidents, this is potentially due to changes in population over the years. From the start of approval of licenses, there seems to be an upward trend in the rate of large-scale marijuana seizures within these counties, the trend is increasing (Figure 6). To better understand this relationship and if these changes in the rates are occurring due to the number of licensed businesses - we ran an OLS regression model accounting for police proactivity. From this model we see a slight increase in crime rates for this offense that is associated with the number of licensed businesses, however, this relationship is not statistically significant. Additionally, the p-value for the coefficient .06 is just above 
conventional significance levels (Table 3). It is possible that other influences are impacting this relationship and the legal businesses only have a small impact. Within this model, we are only able to explain a small amount (11\%) of the variation.

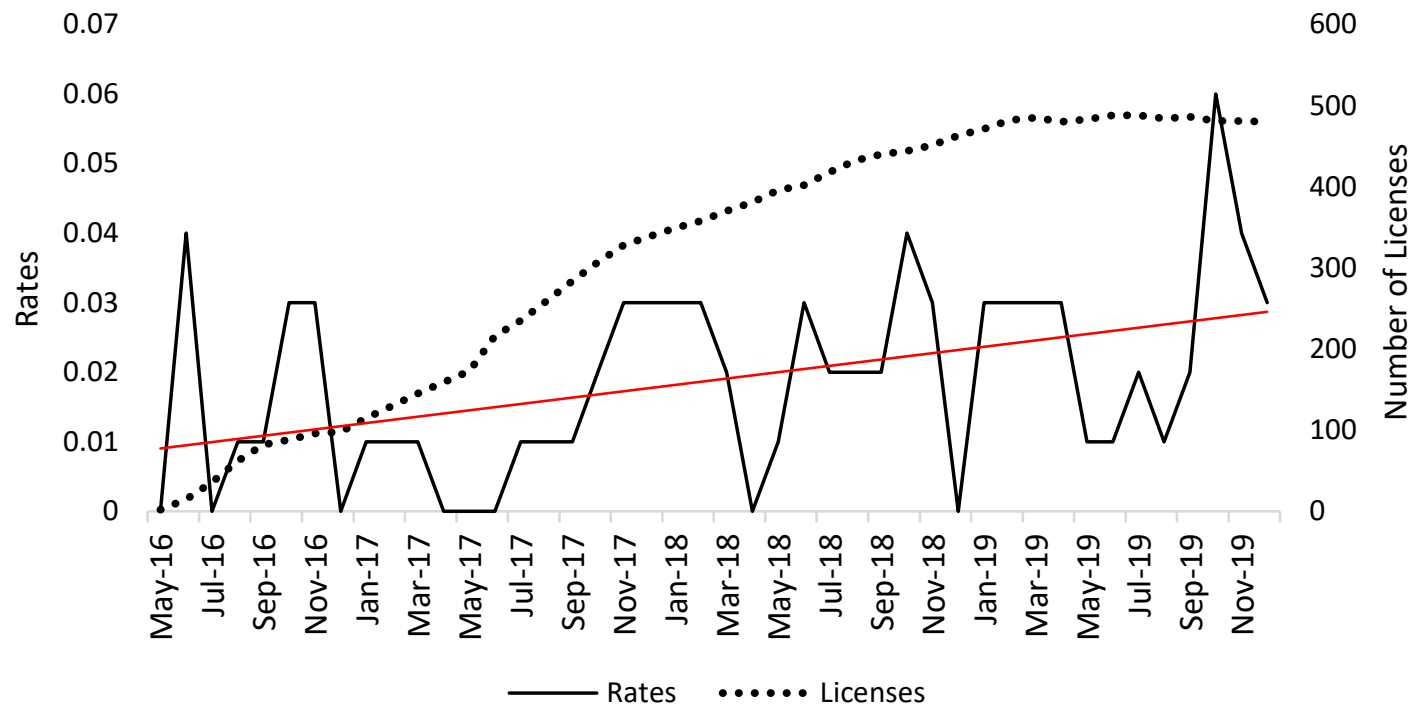

Figure 7. Rates per 100,000 Large-Scale Marijuana Seizures in Transport Settings (2016 to 2019)

In analyzing the rates of large-scale marijuana seizures in a transport setting while controlling for population changes, we see the opposite trend; in the previous examination, we see a stable trend upon legalization. In looking at crime rates we are seeing an increasing trend since the opening of legal businesses (Figure 7). To better understand this relationship and whether it is impacted by the number of licensed businesses - we ran a model controlling for police proactivity. From this model we are seeing a slight increase in rates for this offense associated with the number of licensed businesses, this relationship is statistically significant $(\mathrm{P}<.05)$. Within this model, a decent amount $(22 \%)$ of the variation is explained, providing evidence that this 
relationship is occurring (Table 3). Although this increase is minuscule, it does provide some evidence that the number of licenses is having an impact on the number of largescale seizures involving more than 226 grams within a transport setting. These findings provide support for our hypothesis, as the number of licenses is increasing, we see an increase in crime rates.

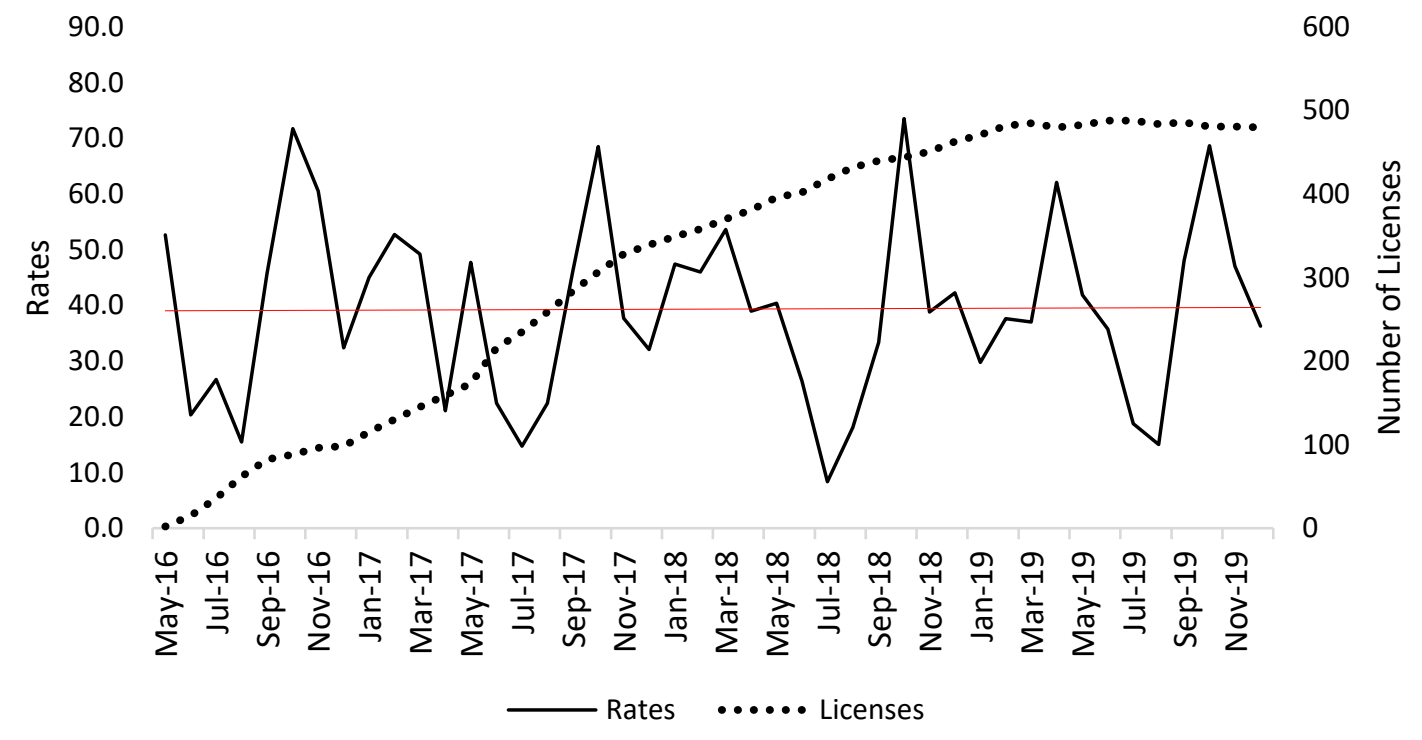

Figure 8. Rates per 100,000 MJ Seizures for Youth Under 18 (2016 to 2019)

As for MJ seizures for youth under 18 within the targeted areas, there seems to be no association between the number of licensed businesses and rates. The peaks in rates do not correspond with the increases in the number of licenses (Figure 8). To better examine this relationship and whether there is an association - we ran a model with the number of licenses while controlling for police proactivity. Within this model, we do see a negative relationship between the number of licensed businesses and rates. The number of licensed businesses could potentially be decreasing the rates for this offense, but its impact is 
minuscule. Additionally, this model does not meet statistical significance and only explains a very small amount (5\%) of the variation (Table 3), suggesting that there could be other influences that are impacting these rates that are unaccounted for. These findings do not support our hypothesis; for this offense, we are not seeing an increase as the number of licenses increases.

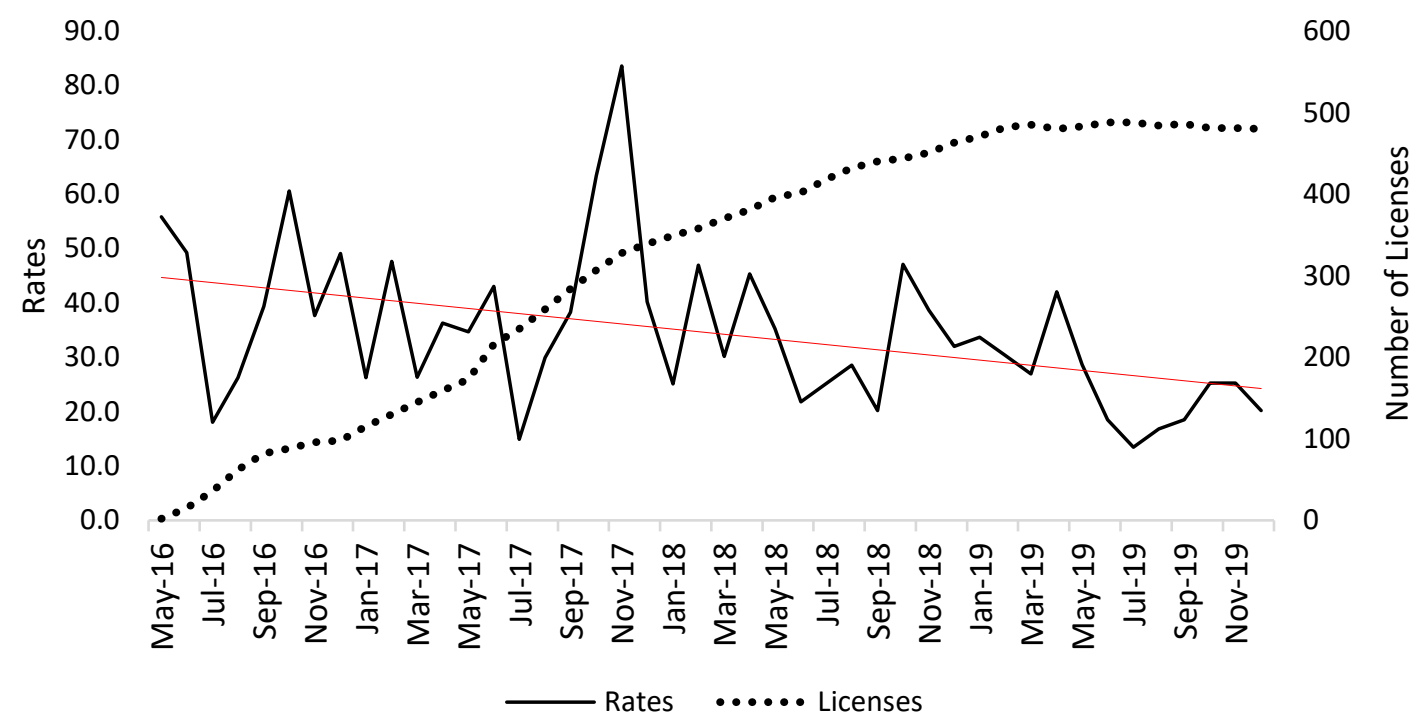

Figure 9. Rates per 100,000 MJ Seizures Ages 18 to 20 (2016 to 2019)

As is the case with previous findings, we see a decreasing trend for rates of incidents where MJ is seized among young adults ages 18 to 20 . The presence of licensed businesses seems to have a negative relationship with the rates for this offense (Figure 9). To better understand this relationship and whether there is an association - we ran an OLS regression model controlling for police proactivity. In this model we see that the number of licensed businesses has a negative impact on the rates for this offense, this is statistically significant $(\mathrm{P}<.01)$. Within this model, a decent amount $(30 \%)$ of the 
variation is explained, providing support for this relationship. The commercialization of MJ has furthered the decreasing trend for these incidents and has had a moderate impact on these rates (Figure 9; Table 3). These findings are inconsistent with our hypothesis, we found the opposite of what was expected.

Table 3.

OLS Regression - Marijuana Seizures Rates per 100,000 (2016 - 2019)

\begin{tabular}{|c|c|c|c|c|c|c|c|c|c|c|c|c|}
\hline & \multicolumn{3}{|c|}{ Large-Scale MJ Seizures } & \multicolumn{3}{|c|}{$\begin{array}{c}\text { Large-Scale MJ Seizures in } \\
\text { Transport Setting }\end{array}$} & \multicolumn{3}{|c|}{$\begin{array}{c}\text { MJ Seizures for Youth } \\
\text { Under } 18\end{array}$} & \multicolumn{3}{|c|}{$\begin{array}{c}\text { MJ Seizures Ages } 18 \\
\text { to } 20\end{array}$} \\
\hline & B & $\mathrm{SE}$ & $\beta$ & B & SE & $\beta$ & B & SE & $\beta$ & B & SE & $\beta$ \\
\hline \multicolumn{13}{|l|}{ Market } \\
\hline Licenses & 0.0000497 & 0.00 & 0.21 & $0.00003295^{*}$ & 0.00 & 0.35 & -0.002 & 0.02 & -0.024 & $-0.039 * k$ & 0.01 & -0.45 \\
\hline \multicolumn{13}{|c|}{ Police Proactivity } \\
\hline Other Drugs & 0.00 & 0.00 & 0.00 & $0.0^{*}$ & 0.00 & -0.58 & -0.068 & 0.06 & -0.204 & 0.048 & 0.05 & -0.15 \\
\hline F statistic & 3.04 & & & 7.50 & & & 1.28 & & & 10.92 & & \\
\hline R-squared & 0.11 & & & 0.22 & & & 0.05 & & & 0.30 & & \\
\hline Significance & 0.057 & & & 0.001 & & & 0.288 & & & 0.001 & & \\
\hline $\mathrm{N}$ & 54 & & & 54 & & & 54 & & & 54 & & \\
\hline
\end{tabular}


RQ 3 - Is there a positive relationship between the amount of legally MJ produced each month in Oregon and the number of targeted MJ-related offenses?

H: We should see an association between the amount of legally produced MJ and the number of MJ-related offenses.

Although the rapid growth in the number of licenses was of great concern, another aspect of legalization that has spurred concern is the quantity of production. Most of the MJ grown in Oregon occurs outdoors and follows a seasonal trend across the years. Certain months produce the most MJ and while production tends to differ across licensees, the aggregated total within a few months far exceeds the amount that is cultivated throughout the rest of the year. The first legal harvest was reported in July 2016 and the amount that is produced yearly has increased in size since. For these analyses, we chose to examine crime rates in comparison to the production of $\mathrm{MJ}$, and to assess the impact of the legal production on MJ-related offense rates we will be running OLS regressions. 


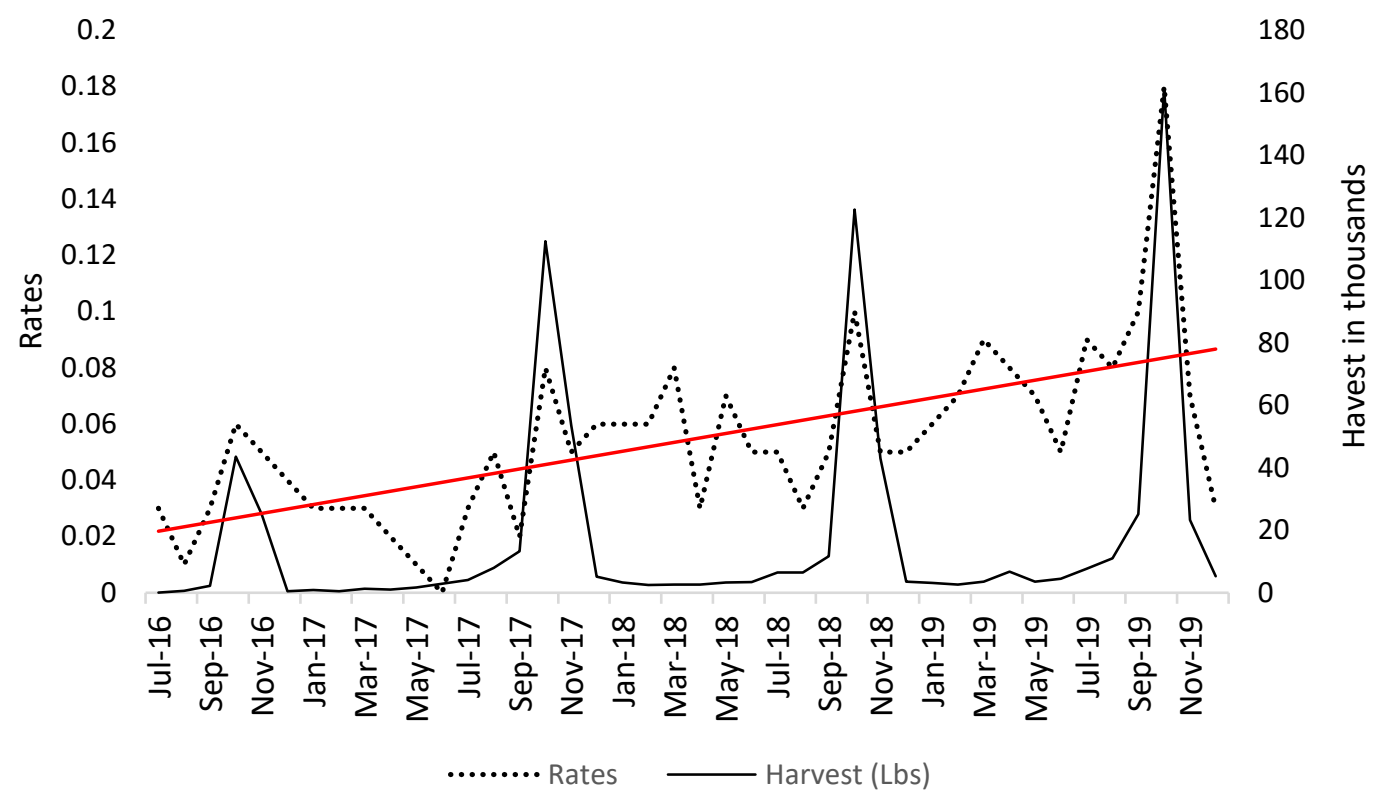

Figure 10. Rates per 100,000 Large-Scale MJ Seizures (2016 to 2019)

While the number of licensed businesses had a minor impact on these rates, there seems to be a greater association between the peaks in rates for large-scale MJ seizures involving more than 226 grams and peaks in production. The trend in seizure rates has gradually increased following the fall production season in 2017; before this season these rates seemed to be declining with a month where the incident rate was 0 (Figure 10). This time frame (2017) has also been associated with the beginning of the flooding of the market (OLCC, 2019). To better understand this relationship and the impact the amount of production has on crime rates - we ran an OLS regression model while controlling for police proactivity. Within this model there seems to be a positive relationship between 
the rates for these offenses and the harvest; this is statistically significant $(\mathrm{P}<.001)$. This model explains a decent amount (30\%) of the variation, providing support for this relationship (Table 4). It also adds to the previous findings that the current market causes an increase in these rates, with the amount of production having a greater impact than the number of licensed businesses. These findings provide support for our hypothesis that there is a positive association between the amount of production and rates for large-scale marijuana seizures.

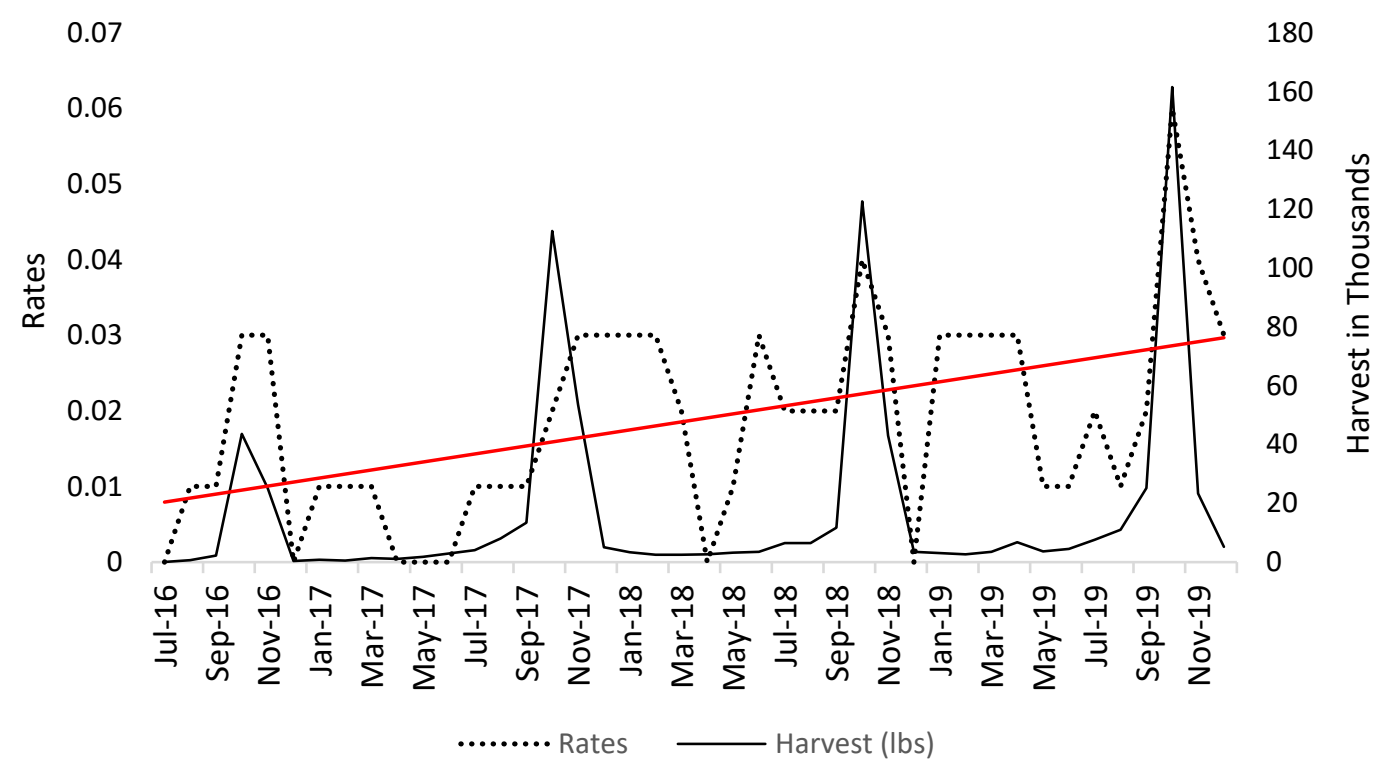

Figure 11. Rates per 100,000 Large-Scale MJ Seizures in a Transport Setting (2016 to 2019)

In analyzing large-scale MJ seizures in a transport setting, we see a very similar association between the harvest months and rates. Throughout the years we see an increase in rates corresponding to the months of heavy production with a difference in rates before the flooding of the market (2017) and afterward. Before the fall production in 2017 the rates for these incidents were declining with rates hitting 0 and this rate of 0 
plateaus for a few months. After the fall production in 2017 we see an increase in rates during the months of production and continuous rates for this offense in between production seasons, from the rates hitting plateaus it suggests that these offenses are ongoing. As the years go by the peaks in these rates start to coincide with the production season (Figure 11). To better examine this relationship - we ran an OLS regression model controlling for police proactivity. In doing so we do see a relationship between these offenses and the harvest amount. The harvest amount is associated with a slight increase for these rates; this relationship is statistically significant $(\mathrm{P}<.001)$. Within this model, we can explain a greater amount (44\%) of the variation providing support for this relationship. In addition, it adds to the previous findings, that there are certain aspects of the current regulatory framework that induce an increase in these rates. These findings provide support for our hypothesis, there is a positive relationship between the harvest amount and the rates for this offense.

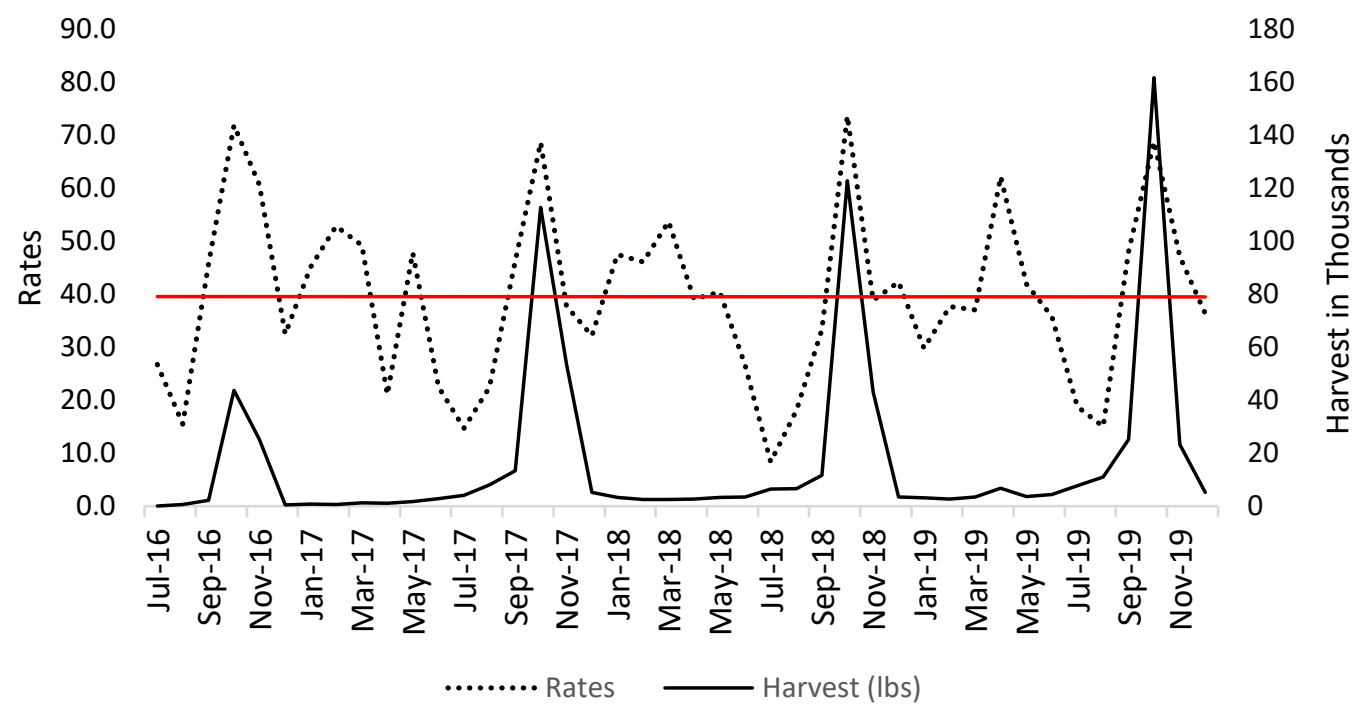

Figure 12. Rates per 100,000 MJ Seizures for Youth Under 18 (2016 to 2019) 
For incidents involving MJ seized for youth under 18, there seems to be an association between the peaks of the harvest and the highest rates (Figure 12). In looking at the highest rates there seems to be a seasonal effect, where these rates correspond to the months with the most production. However, there are still peaks in between the months where most of the harvest is produced and rates do not decrease or hit zero, rather the trend for this offense remains stable (Figure 12). To better understand this relationship and whether there is an association between the amount of production and an impact on this type of incidents - we ran an OLS regression controlling for police proactivity. From this model, we see a positive association between the harvest amount and these rates, this relationship is statistically significant $(\mathrm{P}<.01)$. However, this model only explains a small amount (23\%) of the variation, possibly inferring that there could be other influences that are impacting these rates, as there are peaks in rates in the months between the harvest (Table 4; Figure 12). We are also seeing a different trend than in the previous analyses looking at counts, when we control for population changes the trend for this type of offense remains stable. In the previous findings, it seemed that legalization had led to a decrease in the average number of incidents and rates, but the trend upon legalization was not as steep. It is possible that legalization has created some availability, and that is potentially due to the amount of the harvest produced. From 2018 and forward the peaks in rates in-between seasons are greater. These findings provide support for our hypothesis that there is an association between harvest amount and rates of incidents where MJ was seized for youth under 18. 


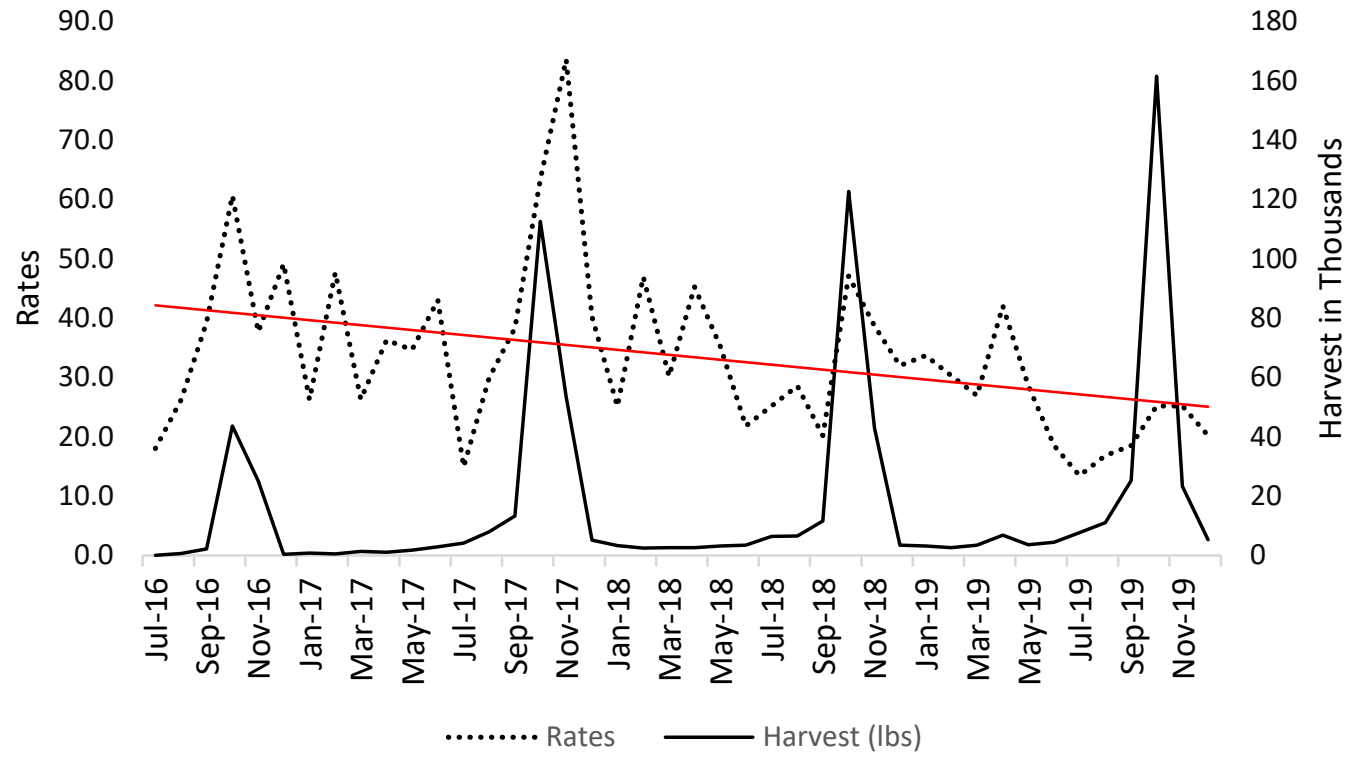

Figure 13. Rates per 100,000 MJ Seizures for Ages 18 to 20 (2016 to 2019)

In the previous findings we found that the number of licensed businesses has a negative impact on the rates for incidents involving the seizure of MJ for ages 18 to 20, and in these analyses, there does seem to be an association between the rates for these offenses and harvest amount. We see a similar trend as with previous findings where peaks for these rates correspond to months of heavy production. Although for these types of incidents, we see a decrease in rates after the 2017 fall production. To better understand this relationship and whether there is an association - we ran an OLS regression model controlling for police proactivity, and the findings are inconclusive. For this model we see an increase in rates associated with the harvest, however, this relationship does not meet statistical significance. The p-value coefficient is above the 
conventional significance level (.12), and only a small amount (10\%) of the variation is explained. Other influences that are unaccounted for could be impacting this relationship.

Table 4.

OLS Regression - Marijuana Seizures Rates per 100,000 (2016 - 2019)

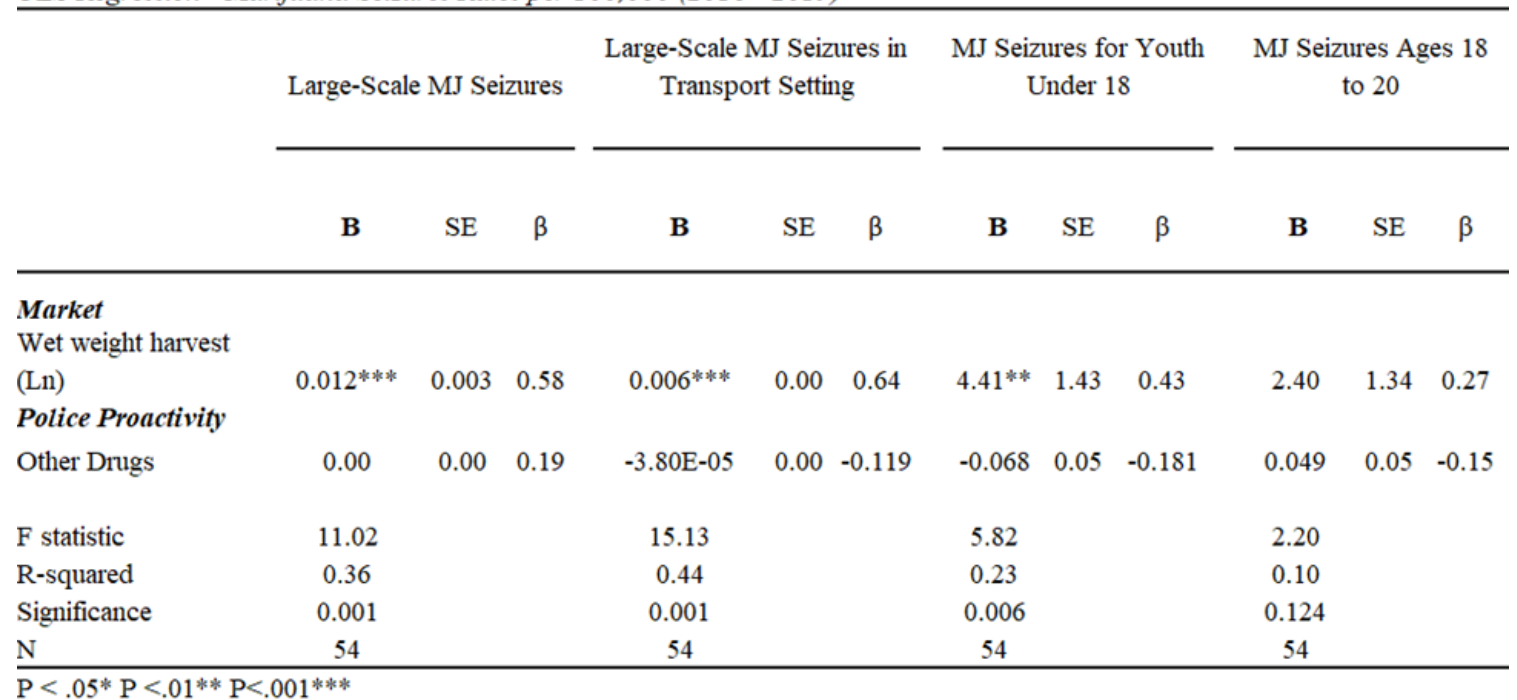




\section{Discussion}

The current study is one of the first efforts to look at the impact of the legalization of RM on marijuana seizures. Contrary to anecdotal accounts and reported increases in marijuana seizures, the legalization of RM has not led to an increase in the number of incidents for large-scale MJ seizures, large-scale MJ seizures in a transport setting, nor incidents where MJ was seized among youth under 18 or ages 18 to 20 within the counties we examined. While there have been no increases, legalization has not completely diminished these types of offenses/incidents. These findings are similar to what was found in a study conducted by Song (2019). That is, there are still occurrences of marijuana-related incidents after legalization. It also adds to the study conducted by Wu and Colleagues (2020) that posited that the crime exacerbation effect in Oregon upon legalization might be due to the presence of a black market. From our findings there seems to be evidence for the presence of an illegal market in Oregon, as youth under the age of 18 still have access to MJ.

When it comes to the implementation of the legal MJ market in Oregon, the number of licensed businesses has impacted the rates for large-scale MJ incidents involving more than 226 grams in a transport setting. As the number of licensed businesses increased it has had an impact on these rates. This provides evidence that the competitive market induces an increase in possible exportation activities. As the number of licensed businesses had a greater impact on the rates for this offense when compared to the rates for large-scale MJ seizures. In a study conducted by Contreras and colleagues (2017), they also found an association between a licensed business (dispensary) and an 
increase in crime in the surrounding areas, which posited the idea that the commercialization of MJ may have some criminogenic features. From our findings, we see an association between the number of licensed businesses and an increase in rates.

The feature of commercialization that had an impact across most rates (large-scale MJ seizures, large-scale MJ seizures in a transport setting, and MJ seized for youth under 18) was the monthly amount of legally produced MJ. There is also an association between the months of heavy production and peaks for these rates. These findings provide support for anecdotal accounts that the overproduction and implementation of RM in Oregon have impacted marijuana-related criminal activity (Williams, 2018; Henning \& Stewart, 2021).

While one of the main proposed arguments for the legalization of RM was that the legal market would reduce black market activity by reducing the number of customers. It seems that legalization has not been able to completely diminish the activity associated with this market. As such, in 2018 Senate Bill 1544 was passed creating the Illegal Marijuana Enforcement Market Program (IMME). The IMME grant provides funding to law enforcement agencies to combat the illegal marijuana market. Additionally, in 2019, Oregon passed Senate Bill 219 allowing for the OLCC to pause licensing for an unlimited amount of time or the time the commission deems necessary. Thus, providing the OLCC time to increase the number of inspectors. Additionally, the secretary of the state of Oregon (2019) recommends changes in data monitoring and the creation of dashboards for each licensee. This would allow for a better projection of the demand and how much MJ needs to be produced per licensee to meet this demand. This allocation of funds and 
recommended changes are set forth in efforts to reduce the illegal market, the impact of overproduction as well as gain control on production, and stabilize the market.

\section{Limitations}

There are several important limitations with the current research. Primarily, there was an inability to distinguish whether large-scale seizures and large-scale seizures in transport settings involved licensed or unlicensed businesses, nor whether they were being exported out of state. It does, however, provide insight into illegal MJ-related activities. Additionally, the sample did not include border counties to Idaho, the only state that surrounds Oregon that has not legalized recreational marijuana use. One caveat is that most of the MJ that is produced within the state resides within these locales. If border counties were included, there may still be similar findings. As the Oregon State Police (2017) have reported increases in MJ seizures on highways heading out of state. Moreover, to better understand the findings relating to incidents where MJ was seized among youth/young adults, including a survey of preferred MJ intake, may provide insight into increases or decreases. Such that, use of discreet products by youth/young adults, such as vaping, may be difficult to find. Also, this metric (incidents where MJ was seized) does not account for youth that do not get caught. Nonetheless, the metric does allow for exploration of illegal market activity as youth are not legally allowed to purchase from the legal market.

Another limitation was not accounting for the surplus/inventory of MJ. The OLCC was able to provide data for monthly sales through a public records request, however, converting the dried product/derivates to wet weight was a complex process. 
This process included multiple steps and the need to account for the amount of dried MJ that is used to create extracts or other MJ items. The equation used to convert the dried product to wet weight is available through the OLCC 2019 Supply and Demand report. Furthermore, the time frame may not have been able to properly assess the impact of oversupply within Oregon, as the impact may be more visible over the next 5 years. While our metric for MJ availability provides insight into the relationship between the harvest and rates for marijuana seizures, accounting for surplus would strengthen the findings in this study. As for the impact of overproduction, in the 2019 report, the estimated inventory was greater than in previous years, which could lead to greater exportation activity if left unchecked. To conclude other statistical methods may be more robust to examine this phenomenon of legalization, an autoregressive integrated moving average (ARIMA) may be better able to examine the differences between the pre-post legalization as it reduces the impact of errors.

\section{Recommendations}

As more states are moving towards the legalization of RM there is a need to understand what works. From examining the literature and the findings within the current study the strength of the legal market seems to be dependent on three mechanisms creating an equilibrium between supply and demand, compliance checks, and efforts to suppress the illegal black market. These are areas that seem to have an impact on increases in rates for marijuana-related offenses. When considering demand, three aspects should be accounted for - the current user base within the state, taxes/pricing, and marijuana tourists. For instance, Washington has produced less than needed for the 
current user base (Steinmetz, 2014; Lamont, 2019), creating an environment where prices may be high within the legal market. While consumers prefer legal products (Aumlung et al., 2018), the prices and the inclusion of taxes on the product, may lead users to choose an alternative, if available (Washington State Institute, 2019). Additionally, projected demand should include marijuana tourists. For example, upon legalization, Washington experienced a decrease in MJ sales on the Washington-Oregon border upon legalization in Oregon. Similarly, a small border town in Oregon has reported an increase in revenue primarily from MJ sales being made to Idahoans (Fertig, 2020). The legal market may serve users living miles away. In Vermont, it is estimated that a decent number of users purchasing from the legal market live within a 2-hour drive (Caulkins et al., 2017). For states that border non-legalized states the inclusion of MJ tourists is an essential component.

Another aspect that needs to be considered is the number of allotted MJ licenses. Rapid increases in licensees could create a competitive environment that could potentially be conducive to crime if proper measures are not in place. Within the legal MJ industry in Oregon, there have been some reported incidents of diversion. For example, in 2018, product that was represented as destroyed within the Metrc Tracking System was found within the residence of a licensee. Additionally, there was a reported incident of a processor attempting to divert product to Nebraska (OSOS, 2019). In balancing the number of licensees that could meet demand, it would put less strain on monitoring and compliance checks. Moreover, while the number of licenses is an important aspect, the consideration of the number of licenses per county and type is also important, as some of 
these businesses could be criminogenic. For example, a study examining the impact of a dispensary in a neighborhood in Los Angeles found an increase in crime in the nearby neighborhood after the opening of this shop (Contreras, 2017). Thus, the number of licensed MJ businesses within a county could impact crime trends.

Lastly, while the marketplace needs to be carefully created, any efforts to create long-term change upon legalization of MJ involve the suppression of the illegal market. The illegal market adds to the competitive business climate and still allows access among youth. To reduce the illegal market, legislation needs to provide clear guidelines for law enforcement and heavy penalties or fines for individuals still engaging in these activities (Auroil et al., 2019). There need to be active efforts by law enforcement to attack this market and prevent diversion of this product in and out of state (Washington State Institute, 2019). The action of legalization may not be enough to reduce activities associated with the black market. While many states are legalizing RM, one solvable solution to a near-complete reduction of black-market activity would be legalization across of the United States.

Areas for Future Research

There are many areas that could benefit from further exploration, such as examining the impact of different types of MJ markets (i.e., competitive or lottery markets). It could provide insight into what would work and the limitations or consequences within these markets. Other areas that need further exploration are the impact of production/overproduction on youth access and use. Also, in categorizing this 
group into anyone under 18, we fail to account for differences among ages. There could be decreases among one cohort group and increases for another.

While there have been studies looking at marijuana laws in connection to the use of other substances, these studies have primarily focused on MMLs. However, it would be interesting to explore the relationship between RMLs and changes in the use of other substances. The findings related to a decrease in MJ seized among young adults ages 18 to 20 is perplexing and no explanation could be found for the decrease in these types of incidents, but there have been increases in the seizures of other substances. For instance, in Oregon from 2010 to 2019, the trend in seizures of other drugs (heroin and meth) have increased, but no tests were conducted to examine this relationship in this study. Lastly, further research on possible exportation activities would benefit the literature as there might be differences depending on the variations across RMLs. It would also be important to include a comparison group of a state that has not legalized MJ as it could strengthen the findings. 


\section{References}

Acker (2019) 95 Cities and counties in Oregon where it is still illegal to sell marijuanaOregonlive.com. Retrieved April 19, 2021, from https://www.oregonlive.com/lifeand-culture/erry-2018/10/5f572c019b9023/95-cities-and-counties-in-oreg.html

Alexander, M., \& West, C. (2012). The new Jim Crow: Mass incarceration in the age of colorblindness (Revised edition). New Press.

American Civil Liberties Union. (n.d.). Marijuana Arrests by the Numbers. American Civil Liberties Union. Retrieved November 2, 2020, from https://www.aclu.org/gallery/marijuana-arrests-numbers

Auriol, E., Mesnard, A., \& Perrault, T. (2019). Defeating Crime? An Economic Analysis of Cannabis Legalization Policies. 58.

Ballotpedia (2014) Oregon Legalized Marijuana Initiative, Measure 91. Ballotpedia. Retrieved October 25, 2020, from https://ballotpedia.org/Oregon_Legalized_Marijuana_Initiative,_Measure_91_(2014 )

Bieber, C. (2021, March 2). Marijuana Tax Revenue: A State-by-State Breakdown. The Motley Fool. https://www.fool.com/research/marijuana-tax-revenue-by-state/

Cerdá, M., Wall, M., Keyes, K. M., Galea, S., \& Hasin, D. (2012). Medical Marijuana Laws in 50 States: Investigating the Relationship between State Legalization of Medical Marijuana and Marijuana Use, Abuse and Dependence. Drug and Alcohol Dependence, 120(1-3), 22-27. https://doi.org/10.1016/j.drugalcdep.2011.06.011 
Contreras, C. (2017). A Block-Level Analysis of Medical Marijuana Dispensaries and Crime in the City of Los Angeles. Justice Quarterly, 34(6), 1069-1095. https://doi.org/10.1080/07418825.2016.1270346

Danko (2019) Oregon recreational marijuana tax revenue surged in 2019-Portland Business Journal. Retrieved April 21, 2021, from https://www.bizjournals.com/portland/news/2019/07/25/oregon-cannabis-tax$\underline{\text { revenue-gets-higher-and-higher.html }}$

Drug Enforcement Agency (1980_1985)

Dragone, D., Prarolo, G., Vanin, P., \& Zanella, G. (2019a). Crime and the Legalization of Recreational Marijuana. Journal of Economic Behavior \& Organization, 159, 488501. https://doi.org/10.1016/j.jebo.2018.02.005

Fertig, N. (2020). Border weed: How the hometown of tater tots became a cannabis capital. POLITICO. Retrieved April 19, 2021, from https://www.politico.com/news/2021/04/18/ontario-oregon-marijuana-481211

Firth, C. L., Maher, J. E., Dilley, J. A., Darnell, A., \& Lovrich, N. P. (2019). Did Marijuana Legalization in Washington State Reduce Racial Disparities in Adult Marijuana Arrests? Substance Use \& Misuse, 54(9), 1582-1587. https://doi.org/10.1080/10826084.2019.1593007

Gallup Poll (2020, November 9). Support for Legal Marijuana Inches Up to New High of 68\%. Gallup.Com. https://news.gallup.com/poll/323582/support-legal-marijuanainches-new-high.aspx 
Gettman, J., \& Kennedy, M. (2014). Let it grow-The open market solution to marijuana control. Harm Reduction Journal, 11(1), 32. https://doi.org/10.1186/1477-7517-11$\underline{32}$

Gramlich, (2020). Four in ten U.S. drug arrests in 2018 were for marijuana offenses mostly possession. Pew Research Center. https://www.pewresearch.org/fact$\underline{\operatorname{tank} / 2020 / 01 / 22 / \text { four-in-ten-u-s-drug-arrests-in-2018-were-for-marijuana-offenses- }}$ $\underline{\text { mostly-possession/ }}$

GSS Poll (2019) National Poll Finds 61 Percent of Americans in Favor of Legalizing Marijuana. Retrieved April 23, 2021, from https://hightimes.com/news/nationalpoll-finds-61-percent-americans-favor-legalizing-marijuana/

Harris, K. D. (2019). S.2227 - 116th Congress (2019-2020): MORE Act of 2019 (2019/2020) [Webpage]. https://www.congress.gov/bill/116th-congress/senate$\underline{\text { bill/2227 }}$

Harpin, S. B., Brooks-Russell, A., Ma, M., James, K. A., \& Levinson, A. H. (2018). Adolescent Marijuana Use and Perceived Ease of Access Before and After Recreational Marijuana Implementation in Colorado. Substance Use \& Misuse, 53(3), 451-456. https://doi.org/10.1080/10826084.2017.1334069

Hausfeld (2016) Oregon's Counties Still Living Under Cannabis Prohibition, Mapped. Willamette Week. (n.d.). Retrieved April 19, 2021, from https://www.wweek.com/cannabis/2016/07/26/oregons-dry-counties-still-livingunder-cannabis-prohibition-mapped/

Henning, D. K., \& Stewart, G. (2019). Illegal Marijuana Markets Enforcement Grant Program: Deschutes County. 37. 
Henning, K. \& Stewart (2021). Dazed and Confused: Police Experiences Enforcing Oregon's New Marijuana Laws. 7.

Illegal Marijuana Market Enforcement Grant Program (2019) Criminal Justice Commission

Keyes, K. M., Wall, M., Cerdá, M., Schulenberg, J., O’Malley, P. M., Galea, S., Feng, T., \& Hasin, D. S. (2016). How does State Marijuana Policy Affect US Youth? Medical Marijuana Laws, Marijuana Use and Perceived Harmfulness: 1991-2014: MML and attitudes. Addiction, 111(12), 2187-2195. https://doi.org/10.1111/add.13523

King, R., \& Mauer, M. (2006). The War on Marijuana: The Transformation of the War on Drugs in the 1990s Harm Reduction Journal, 3(1), 6. https://doi.org/10.1186/1477-7517-3-6

Lamont (2019) Wholesale Cannabis Shortage Facing Washington State. Kush.Com Blog. https://kush.com/blog/washington-wholesale-cannabis-shortage-2019/

Leafbuyer (2017). Best Places to Grow Weed in Oregon. https://www.leafbuyer.com/blog/growing-weed-what-are-the-best-places-to-growweed-in-oregon/

Lu, R., Willits, D., Stohr, M. K., Makin, D., Snyder, J., Lovrich, N., Meize, M., Stanton, D., Wu, G., \& Hemmens, C. (2019). The Cannabis Effect on Crime: Time-Series Analysis of Crime in Colorado and Washington State. Justice Quarterly, 1-31. https://doi.org/10.1080/07418825.2019.1666903

Makin, D. A., Meize, M. R., Willits, D. W., Stohr, M. K., Hemmens, C., Lovrich, N. P., Nordman, A., \& Stanton, D. (2020). The Impact of Recreational Marijuana Sales on 
Calls for Service: An Analysis of Neighbouring Cities. Policing and Society, 1-15. https://doi.org/10.1080/10439463.2020.1773461

Makin, D. A., Willits, D. W., Wu, G., DuBois, K. O., Lu, R., Stohr, M. K., Koslicki, W., Stanton, D., Hemmens, C., Snyder, J., \& Lovrich, N. P. (2019). Marijuana Legalization and Crime Clearance Rates: Testing Proponent Assertions in Colorado and Washington State. Police Quarterly, 22(1), 31-55. https://doi.org/10.1177/1098611118786255

Marist Poll (2017). Retrieved May 14, 2021, from https://www.criminalcivillawyer.com/wp-content/uploads/Yahoo-News-Marist-PollWeed-and-The-American-Family.pdf

Measure 91-Legislation

Morris, R. G., TenEyck, M., Barnes, J. C., \& Kovandzic, T. V. (2014). The Effect of Medical Marijuana Laws on Crime: Evidence From State Panel Data, 1990-2006. PLoS ONE, 9(3), e92816. https://doi.org/10.1371/journal.pone.0092816

Marijuana Policy Project (2020) State Decriminalization Chart. Retrieved April 19, 2021, from https://www.mpp.org/assets/pdf/issues/decriminalization/State-DecrimChart.pdf

National Survey on Drug Use and Health (2019)

National Research Council. 1982. An Analysis of Marijuana Policy. Washington, DC:

The National Academies Press. https://doi.org/10.17226/662.

Oregonian. (2012). State Measure 80: Legalization of marijuana fails-Oregonlive.com. https://www.oregonlive.com/politics/2012/11/state_measure_80_legalization.html 
Oregon Liquor Control Commission. (2019). 2019 Recreation Marijuana Supply and Demand Legislative Report. Portland, OR: Oregon Liquor Control Commission.

Oregon Liquor Control Commission (2021) Marijuana and Hemp (Cannabis): State of Oregon. Retrieved April 23, 2021, from https://www.oregon.gov/olcc/marijuana/Pages/default.aspx

Oregon Secretary of State (2019) Oregon's framework for regulating marijuana should be strengthened to better mitigate diversion risk and improve laboratory testing.

Oregon State Police (2017) Drug Enforcement Section. A Baseline Evaluation of Cannabis Enforcement Priorities in Oregon. Salem, OR. Oregon State Police.

Oregon Idaho High-Intensity Drug Trafficking Area (2018) An initial assessment of Cannabis Production, Distribution, and Consumption in Oregon

Pew Research (2019). Two-thirds of Americans support marijuana legalization. Pew Research Center. Retrieved October 24, 2020, from https://www.pewresearch.org/fact-tank/2019/11/14/americans-support-marijuanalegalization/

Plunk, A. D., Peglow, S. L., Harrell, P. T., \& Grucza, R. A. (2019). Youth and Adult Arrests for Cannabis Possession After Decriminalization and Legalization of Cannabis. JAMA Pediatrics, 173(8), 763. https://doi.org/10.1001/jamapediatrics.2019.1539

Pugmire (2021) MN House passes legal cannabis bill; no future in Senate. MPR News. Retrieved May 14, 2021, from https://www.mprnews.org/story/2021/05/13/housepasses-legal-cannabis-bill-no-future-in-senate 
Reinarman et al (2011). Who are Medical Marijuana Patients? Population Characteristics from Nine California Assessment Clinics. J Psychoactive Drugs. Apr-Jun.

Rosato, C. (2021). Convincing lawmakers to decriminalize marijuana won't be easy. Https://Www.Wafb.Com. Retrieved May 14, 2021, from https://www.wafb.com/2021/05/10/debate-la-house-bill-proposing-legalize$\underline{\text { marijuana-pushed-back-wednesday-may/ }}$

Steinmetz (2014) Washington State Is Low on Legal Pot. Time. Retrieved April 23, 2021, from https://time.com/2946014/marijuana-pot-legalization-washington/

Senate Bill 218 (2019)—License pausage

Shepard, E. M., \& Blackley, P. R. (2016). Medical Marijuana and Crime: Further Evidence From the Western States. Journal of Drug Issues, 46(2), 122-134. https://doi.org/10.1177/0022042615623983

Song, S. (2000). Effects of Regulation Intensity on Marijuana Black Market After Legalization. https://doi.org/10.15760/etd.6919

Stanton, D., Mei, X., Kim, S., Willits, D., Stohr, M., Hemmens, C., Wu, G., Lu, R., Makin, D., \& Lovrich, N. (2020). The Effect of Marijuana Legalization on Jail Populations in Washington State. The Prison Journal, 100(4), 510-530. https://doi.org/10.1177/0032885520939313

Stohr, M. K., Willits, D. W., \& Investigator, C.-P. (n.d.). Effects of Marijuana Legalization on Law Enforcement and Crime: Final Report. Final Report, 158. Stringer, R. J., \& Maggard, S. R. (2016). Reefer Madness to Marijuana Legalization: Media Exposure and American Attitudes Toward Marijuana (1975-2012). Journal of Drug Issues, 46(4), 428-445. https://doi.org/10.1177/0022042616659762 
The National Research Council (1982). Committee on Substance Abuse and Habitual Behavior. An Analysis of Marijuana Policy. Washington, DC: National Academy Press

The NORML Foundation. (2021). NORML. Retrieved April 17, 2021, from https://norml.org/about-norml/norml-foundation/

Walsh (2020). The State of the Marijuana Black Market. Brown Political Review. https://brownpoliticalreview.org/2020/01/the-state-of-the-marijuana-black-market/ Washburn. (2019). What we've learned from three years of legal marijuanaOregonlive.com. https://www.oregonlive.com/news/erry2018/06/932fe5664b5193/what_we_know_and_dont_know_aft.html

Washington State Institute for Public Policy (2019) Suppressing Illicit Cannabis Markets After State Marijuana Legalization

Williams, B. (2018). U.S. Attorney: A call for transparency and action on marijuana. Oregon Live. Retrieved from: https://www.oregonlive.com/opinion/2018/01/us_attorney_a_call_for_transpa.html. Whelan, J., \& Msefer, K. (2003) Economic Supply and Demand. 46.

Wu, G., Wen, M., \& Wilson, F. A. (2021). Impact of Recreational Marijuana Legalization on Crime: Evidence from Oregon. Journal of Criminal Justice, 72, 101742. https://doi.org/10.1016/j.jcrimjus.2020.101742 